\title{
Novel Theoretical Approach to the Filtration of Nano Particles Through Non-Woven Fabrics
}

\author{
Nikola Jakšić ${ }^{1}$ and Danilo Jakšić ${ }^{2}$ \\ ${ }^{1}$ Turboinštitut \\ ${ }^{2}$ University of Ljubljana \\ Slovenia
}

\section{Introduction}

The motivation for this work comes from studying the composition of a medical face mask made of non woven fabrics and the mechanisms of filtrations inside the mask. Present medical mask filters passing air with the maximum efficiency of $99.97 \%$, which might be seen as excellent. Main question is: "What presents this $0.03 \%$ ?" If an aggressive virus is found in this tiny share, the effectiveness of the mask would be questionable.

The filtration mechanism in a non woven fabric is a complex process. It is obvious that air passing through a non woven fabric has to go through voids in the fabric. In order to understand the filtration mechanism, it is essential to be able to define fabrics porosity parameters, the nature of the air flow through voids in the fabric and the behaviour of the nano-particle caught inside the flow.

The classical theory of filtration is based on a single fibre in the fluid flow; Sharma (2000),Brown (1993), and Hutten (2007). It neglects neighbouring fibres and thus all porosity parameters. It was reasonable simplification due the fact that no easy method that would be reliable at the same time did exist until J-method for assessing the flat textiles porosity was introduced in Jakšić \& Jakšić (2007) and Jakšić \& Jakšić (2010). J-method enables us to determine all relevant porosity parameters, which makes this approach to filtration possible.

Medical face masks, which are made of textile fibres, are light, easy to use, relatively low-cost, and very efficient in combating air-borne infections. The mask design should provide tight fit to the skin of a face in order to ensure that air flows only through the mask. The design of the mask should also ensure filtration, not only dust particles, but also microbes and viruses. The masks are meant for a single use to avoid saturation of a mask. They are also suitable for use in a dust environment until saturation of a mask.

The mask composition must be proper regarding its use. The filtering layer must be protected with additional layers at its side faced towards a subject's face and outside side. Voids (pores) in the inner layer, which is actually filter passing air, should not lead air from the outer side to the inner side of the layer directly, as a channel. The dust particles, microbes and viruses might penetrate a mask designed in that way by being trapped in the unobstructed air flow. Pores in the inner layer, that enables air flow through mask, should be small enough and winded like a channel frequently changing its direction, in order to ensure maximum filtering efficiency. 
The criteria can only be met with a non-woven fabric made of microfibers. The diameter of microfibers is normally between $1.5 \mu \mathrm{m}$ and $2.5 \mu \mathrm{m}$. For comparison, the diameter of normal chemical fibres is normally around $20 \mu \mathrm{m}$.

The medical face mask analysed here is made of three non-woven fabrics layers of different quality. The outer and inner fabric are intended for the partial filtration only and primarily for the protection of the filtration fabric in the middle. Fibres in all three fabrics are placed in the random pattern enhancing air-flow filtration capability.

The arguments focused on the nature of the air flow through a fabric and the behaviour of the nano-particle caught inside the flow were made based on analytical and numerical analysis computational fluid dynamics (CFD).

The novel approach to the filtration of nano-particles through non-woven fabrics is based on a fabric porosity and consequently on the nature of the fluid flow through the fabric. It is thus essential to quickly recapitulate the method for estimating the porosity of flat textiles (J-method); Jakšić \& Jakšić (2007) and Jakšić \& Jakšić (2010). The design and the porosity parameters of the mask under consideration are presented next followed by description of the mechanisms of filtration in the mask.

\section{$1.1 \mathrm{~J}$-method for determining porosity of flat textiles}

The method is based on selectively squeezing the fluid in the pores out of the wet fabrics by air pressure and on the presumption that a pore is approximated with a cylinder. The selectivity is assured by the fact that the fluid is squeezed out of the pores with a certain hydraulic diameter providing that the precise value of the air pressure is applied. The air pressure is inversely proportional to the hydraulic pore diameter. Latter is important, while the process of squeezing out the fluid contained in the pores of the wet fabrics is under examination. There is always a small amount of the fluid that remains at the edges of pores if such edges exist.

We worked under two presumptions:

- The regime of the air flow through the dry and the wet sample is the same at same pressure difference regardless of the size of the open area of the wet sample.

- The number of the hydraulic pores is not the same as number of pores between threads of the warp and weft if the ratio of the rectangular sides, which represents real pore's cross-section, is at least 3:1.

The pressure difference $p_{i}$ between the opposite surfaces of the flat textile, equation (1), results in squeezing the fluid out of the pores, which diameter is equal or larger than $d_{i}$. The fluid is characterized by the surface stress $\alpha$.

$$
d_{i} \geq \frac{4 \alpha}{p_{i}}
$$

The fluid is first squeezed out from pores, which have the largest hydraulic diameter. The flow of air will establish itself through these pores that are now empty. The volume flow rate of air through the flat textile can be described by equation (2)

$$
V_{i}=A p_{i}=P a p_{i}^{b}=P v_{i}
$$


where $V_{i}$ stands for the air volume flow rate through the sample at the air pressure pi, $A$ for a regression coefficient when fitting equation (2) to the measured dry data, $P$ for the open surface, $v_{i}$ for the linear air flow velocity, $a$ for the coefficient and $b$ for the exponent. The parameters $a$ and $P$ are unknown and they have to be estimated as well. The solution of the problem is enabled by equation (3) by putting the velocity $v_{i}$ in the relationship with the air pressure $p_{i}$. The value for the exponent $b$ is bounded between 0.5 and 1.0. The last part of equation (3) holds in the ideal circumstances, when all of the energy dissipation mechanisms are neglected.

$$
v_{i}=a_{0} p_{i}^{b}=1.28 p_{i}^{0.5}
$$

The selective squeezing out the fluid from pores enables us to compute the number of pores at each interval defined by the incremental pressure growth. The number of pores in the $i^{\text {th }}$ interval as

$$
n_{i}=\frac{p_{i}^{2}}{4 \pi a \alpha^{2}}\left(\frac{V_{i}}{p_{i}^{b}}-\frac{V_{i-1}}{p_{i-1}^{b}}\right)
$$

The presumption of the equal regime of the air flow through the wet sample's open area and the dry one at the same pressure is taken into account. Small values of the Reynolds number in the extreme causes (maximal hydraulic diameter of pore), support that presumption. The air flow is either laminar through the open pores in the wet sample and through all pores in the dry sample, or the type of the air flow is same. This is the criterion for using the exponent $b$, which is estimated when equation (2) is fitted to the measured dry data, in the process of determining the pore distribution from the measured wet data. The corresponding coefficient $a_{j}$ are determined by equation (5)

$$
a_{j}=1.28 \frac{n_{c j}}{n_{t}}=\frac{1.28}{a^{*}} \quad ; \quad a^{*}=\frac{n_{t}}{n_{c j}}
$$

where $n_{t}$ stands for the true number of pores, $n_{c j}$ for the computed number of pores and $a_{j}$ for the corrected $a$ in equation (4). The values of theoretical limits, for exponent $b\left(b_{0}=0.5\right)$ and coefficient $a\left(a_{0}=1.28\right)$, that are used in the second procedure are shown in the last part of equation (3).

Four different samples were used for the method's testing, which practically encompasses all the fabric types that the method is suitable for. The basic design parameters of the woven fabrics are presented in table 1 . They are made of monofilament, multifilament and cotton yarn. The measured average pore's hydraulic diameters of the textiles are in the interval of 18 up to 200 micrometers. The wide assortment of textiles is thus covered.

The results of the textile's porosity tests are presented in table 2. The first procedure is used for all four samples. The second procedure was used for porosity parameters estimation of samples (a) and (b) due to large value of the parameter $a_{0}$.

The nomenclature in table 2 - $b$ stands for the exponent in equation (2), $h[\mu \mathrm{m}]$ for the width of the interval of the pore distribution, $m$ for the number of the distribution intervals, $n_{t}$ for the true number of pores between the threads of the warp and the weft per $\mathrm{cm}^{2}, n$ for the computed number of hydraulic pores between the threads of the warp and the weft per $\mathrm{cm}^{2}$, when the true number of pores (or number of hydraulic pores) is unknown (second procedure), $d$ for the average hydraulic diameter of pores, $d_{t}$ for the optically measured average hydraulic pore diameter - for samples (b), (c) and (d); the pores are ill-defined in 


\begin{tabular}{|c|l|c|c|c|}
\hline Sample & Description & $\begin{array}{l}\text { Measurement } \\
\text { interval }[\mu \mathrm{m}]\end{array}$ & $\begin{array}{c}\text { Number of } \\
\left.\text { [pores per cm }{ }^{2}\right]\end{array}$ & $\begin{array}{c}\text { Warp / weft } \\
\text { [threads per cm] }\end{array}$ \\
\hline \hline (a) & Cotton woven fabric & $160-20$ & 452 & $22 / 21$ \\
\hline (b) & $\begin{array}{l}\text { Thick monofila- } \\
\text { ment fabric }\end{array}$ & $80-10$ & 2200 & $55 / 40$ \\
\hline (c) & $\begin{array}{l}\text { Multifilament } \\
\text { woven fabric }\end{array}$ & $270-140$ & 960 & $32 / 30$ \\
\hline (d) & $\begin{array}{l}\text { Very thick monofila- } \\
\text { ment woven fabric }\end{array}$ & $24-12$ & 32400 & $180 / 180$ \\
\hline
\end{tabular}

Table 1. Samples used in the testing of J-method

\begin{tabular}{|l|l|c|c|c|c|}
\hline \multirow{2}{*}{ Porosity test procedure } & \multirow{2}{*}{ Parameter } & \multicolumn{5}{|c|}{ Sample } \\
\cline { 2 - 7 } & & $(\mathrm{a})$ & $(\mathrm{b})$ & $(\mathrm{c})$ & $(\mathrm{d})$ \\
\hline \hline \multirow{4}{*}{$\begin{array}{l}\text { Porosity parameters when } \\
\text { the number of pores is } \\
\text { known (the first procedure) }\end{array}$} & $b$ & 0.5794 & 0.6355 & 0.8329 & 0.7174 \\
\cline { 2 - 7 } & $h[\mu \mathrm{m}]$ & 14 & 10 & 13 & 2 \\
\cline { 2 - 7 } & $n_{t}$ & 10 & 7 & 10 & 7 \\
\cline { 2 - 7 } & $d_{t}[\mu \mathrm{m}]$ & $452^{*}$ & 2200 & 960 & 32400 \\
\cline { 2 - 7 } & $P[\%]$ & 0.98 & 2.07 & 31.32 & 9.06 \\
\cline { 2 - 7 } & $P_{t}[\%]$ & $1.00^{* *}$ & 3.43 & 29.84 & 8.98 \\
\cline { 2 - 7 } & $a_{0}$ & 9.4074 & 2.8236 & 0.28 & 0.8791 \\
\hline \multirow{2}{*}{$\begin{array}{l}\text { Porosity parameters when } \\
\text { the number of pores is } \\
\text { unknown (the second } \\
\text { procedure) }\end{array}$} & $d[\mu \mathrm{m}]$ & 45.00 & 32.77 & & \\
\cline { 2 - 7 } & $P[\%]$ & 6.96 & 6.17 & & \\
\cline { 2 - 7 } & $n$ & 3314 & 6213 & & \\
\hline
\end{tabular}

Table 2. Parameters of porosity estimated with J-method for all four samples. * - the number corresponds to the product of the warp and weft. ${ }^{* *}$ - corresponds to the 452 measured pores - between the threads of warp and weft only one typical pore was measured in each void between the threads of warp and weft.

\begin{tabular}{|l|c|c|c|c|c|c|}
\hline Statistic parameters & $\begin{array}{c}w \\
{[\mu \mathrm{m}]}\end{array}$ & $\begin{array}{c}l \\
{[\mu \mathrm{m}]}\end{array}$ & $\begin{array}{c}d_{t} \\
{[\mu \mathrm{m}]}\end{array}$ & $\begin{array}{c}P_{\text {real }}=w l \\
{\left[\mu \mathrm{m}^{2}\right]}\end{array}$ & $\begin{array}{c}P_{h y d r} \\
{\left[\mu \mathrm{m}^{2}\right]}\end{array}$ & $\frac{l}{d_{t}}$ \\
\hline Mean & 20.13 & 66.06 & 30.00 & 1364.67 & 786.29 & 2.50 \\
\hline Standard deviation & 7.77 & 13.75 & 10.19 & 664.13 & 461.38 & 1.19 \\
\hline Minimum & 4.76 & 23.81 & 8.82 & 287.12 & 61.07 & 1.04 \\
\hline Maximum & 34.92 & 87.3 & 46.91 & 2519.68 & 1727.43 & 6.86 \\
\hline Total & & & & 68233.43 & 39314.56 & \\
\hline
\end{tabular}

Table 3. Results of the scanning-electron microscope pore's shape and open area measurement on 50 pores of the sample (b). 
sample (a), $P[\%]$ for the average open hydraulic flow area, $P_{t}[\%]$ for the average open flow hydraulic area computed on the bases of the optical experiment, $a_{0}$ for the coefficient $a$, equation (2), at presumption that exponent $b$ has minimal value $(b=0.5)$.

When dealing with the sample $(b)$, the average ratio $l / w$ in table 3 is $66.06 / 20.13=3.23$. Hence, the criterion of having more than one hydraulic pore in a pore between threads of the warp and weft is thus met. The maximum value of the ratio between the value of the longer rectangular side $l$ and the hydraulic diameter of the same pore is 6.84 and the mean value is 2.5. Hence, the true number of the hydraulic pores of the specimen (b) is $2200 \cdot 2.5=5500$, see table 2 . The estimated number of hydraulic pores is 6213 , table 2 , which is only $13 \%$ more than the true number of hydraulic pores in specimen (b).

The porosity of the non-woven flat fabrics is extremely difficult to characterize due to their irregular structure. The structure makes them better, more effective filtration media in comparison to the woven fabrics. Hence, the challenge is to estimate their porosity parameters. The experimental results presented in table 2 and 3, especially sample (b), proved that the porosity of the non-woven flat textiles can be estimated by J-method.

\section{Medical mask}

A medical mask fabric is composed of three layers. The outer layer and the layer suite on the face of a subject are composed of fibres which diameter is $18 \mu \mathrm{m}$. The inner layer is composed from microfibers which diameter is $2 \mu \mathrm{m}$, see figures 2 and 3 . In this layer the fibres are arranged in 37 sub-layers.

\subsection{Initial state of a medical mask}

When discussing the mechanisms of filtration the initial state of the mask before usage must be defined:

1. The mask is new and in the original package.

2. The mask is placed over a subject's face in a way that it covers respiratory organs and air can pass only through the mask.

3. The mask assures 100

4. The laminar flow of air through mask is observed.

5. A mask user is moderately active; volume flow: $40-601 / \mathrm{min}$, breathing rate: $12-20$ breaths per minute.

6. The mask thickness is $285 \mu \mathrm{m}$ and specific mass is $57.5 \mathrm{~g} / \mathrm{m} 2$.

7. The fibres for the inner mask layer are randomly orientated and spread over the whole area, see figures 2 and 3 .

8. There are no fibres in the direction perpendicular to the mask face, which means that the non-woven fabric was not needled.

\subsection{Virus}

Viruses are smaller than dust particles and microbes and thus the most difficult to filter out. They come in different shapes: spherical, see figure 1, helical, icosahedra, etc. and sizes, which varies between $10 \mathrm{~nm}$ and $300 \mathrm{~nm}$. The average density of a virus is approximated to $\mathrm{v}$ $=1200 \mathrm{~kg} / \mathrm{m}^{3}$. We will focus on the spherical or near spherical viruses. 


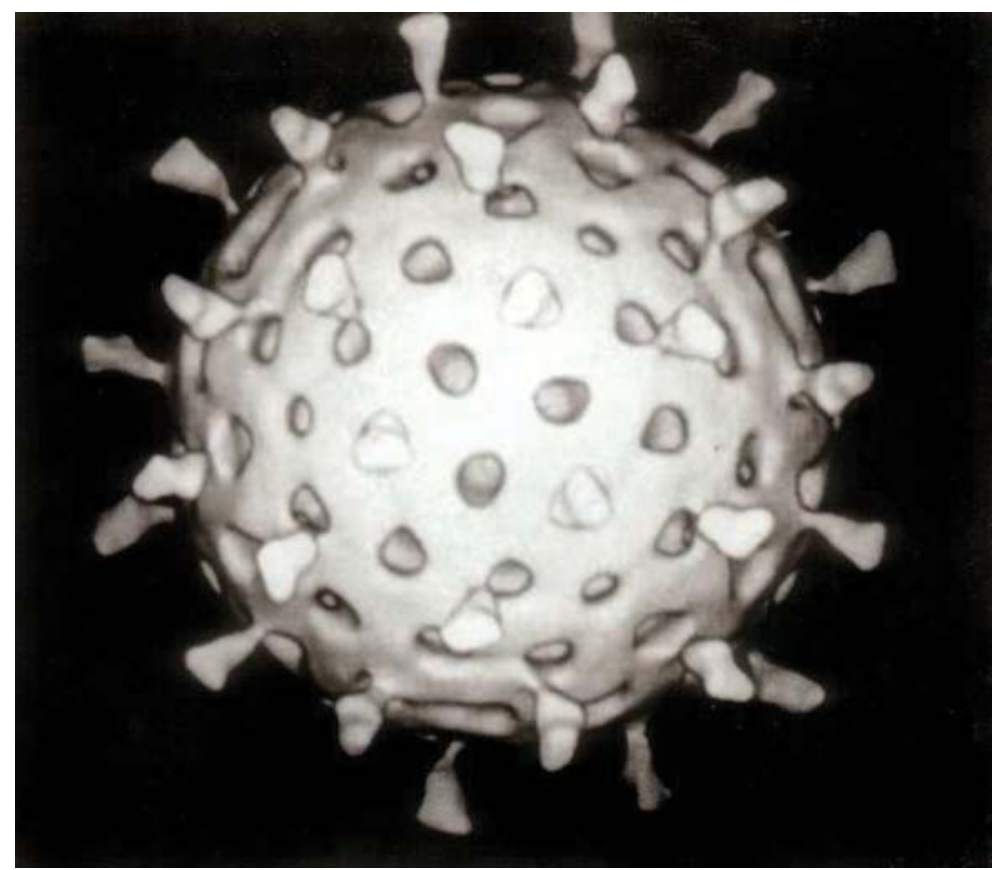

Fig. 1. Computer-aided reconstruction of a rotavirus based on several electron micrographs; Wikipedia (2011)

\subsection{Porosity of the medical masks}

We have applied J-method to characterise the porosity of a medical mask. The walls of pores are defined by fibres. In contrast to a woven fabric, where pores are straight from one surface to the opposite one and where the length of pores is equal to thickness of the fabric, the pores in the non-woven fabric changes its direction and are thus much longer than the fabric's thickness. It is this property that makes them an excellent filtration media and at the same time, very difficult to characterise. Even though the viruses are much smaller than the hydraulic diameter of pores, the configuration of pores allows for high filtration efficiency.

\begin{tabular}{|l|c|l|l|l|l|l|}
\hline Non-woven layer & $\begin{array}{l}\text { Mass } \\
{\left[\mathrm{g} / \mathrm{m}^{2}\right]}\end{array}$ & $\begin{array}{l}\text { Thick- } \\
\text { ness } \\
{[\mu \mathrm{m}]}\end{array}$ & $\begin{array}{l}\text { Number } \\
\text { of fibre } \\
\text { layers }\end{array}$ & $\begin{array}{l}\text { Thick- } \\
\text { ness of } \\
\text { fibres } \\
{[\mu \mathrm{m}]}\end{array}$ & $\begin{array}{l}\text { Active } \\
\text { surface* } \\
{[\%]}\end{array}$ & $\begin{array}{l}\text { Total } \\
\text { surface } \\
{\left[\mathrm{cm}^{2}\right]}\end{array}$ \\
\hline Outer & 17.6 & 92 & 5 & 18 & 87 & 160 \\
\hline Inner & 20.4 & 74 & 37 & 2 & 100 & 160 \\
\hline Outer on the subject face & 19.1 & 120 & 7 & 18 & 75 & 160 \\
\hline
\end{tabular}

Table 4. Comparison of chosen physical parameters of the fibres from which the mask is made. * - not blocked with fibres pressed together

All three layers are made of polypropylene fibres. The area of the mask that allows the air flow is around $160 \mathrm{~cm}^{2}$, table 4 . The active surface of the outer layers is smaller than the active surface of the inner layer. Both outer layers are strengthened for their ability to retain shape 
by pattern of dots where the fibres are partially pressed together. In this way, the parts of the other layers are transformed into a foil. Nevertheless, it is the open surface P that allows the airflow, table 5. The inner layer sub-layers are not pressed nor melted together and hence the air can flow through sub-layers and pores that are actually blocked by the outer layers areas transformed into the foil. Hence, $100 \%$ of active surface of the inner layer reported in table 4 holds.

\begin{tabular}{|l|c|c|c|c|}
\hline Parameters of porosity & $\begin{array}{l}\text { Outer non- } \\
\text { woven layer }\end{array}$ & $\begin{array}{l}\text { Inner non- } \\
\text { woven layer }\end{array}$ & $\begin{array}{l}\text { Outer on the } \\
\text { subject face }\end{array}$ & $\begin{array}{l}\text { Mask (all } \\
\text { three layers) }\end{array}$ \\
\hline \hline The biggest pore $[\mu \mathrm{m}]$ & 305 & 38 & 211 & 30 \\
\hline$d_{\max }[\mu \mathrm{m}]$ & 275 & 28 & 195 & 26 \\
\hline$d_{\min }[\mu \mathrm{m}]$ & 15 & 8 & 15 & 9 \\
\hline$d_{p}[\mu \mathrm{m}]$ & 83.2 & 12.46 & 76.3 & 13.91 \\
\hline$b$ & 0.6183 & 0.7313 & 0.6143 & 0.7521 \\
\hline$A$ & 0.249 & 0.0889 & 0.2925 & 0.0921 \\
\hline$P[\%]$ & 27.71 & 8.43 & 25.32 & 8.42 \\
\hline Width of the classes $[\mu \mathrm{m}]$ & 13 & 2 & 18 & 2 \\
\hline Number of the classes & 13 & 10 & 10 & 10 \\
\hline Number of pores $/ \mathrm{cm}^{2}$ & 3745 & 68414 & 4506 & 45294 \\
\hline
\end{tabular}

Table 5. Parameters of porosity for all three non-woven layers of mask; the surface of samples: $1 \mathrm{~cm}^{2}$; liquid in the pores: n-butanol

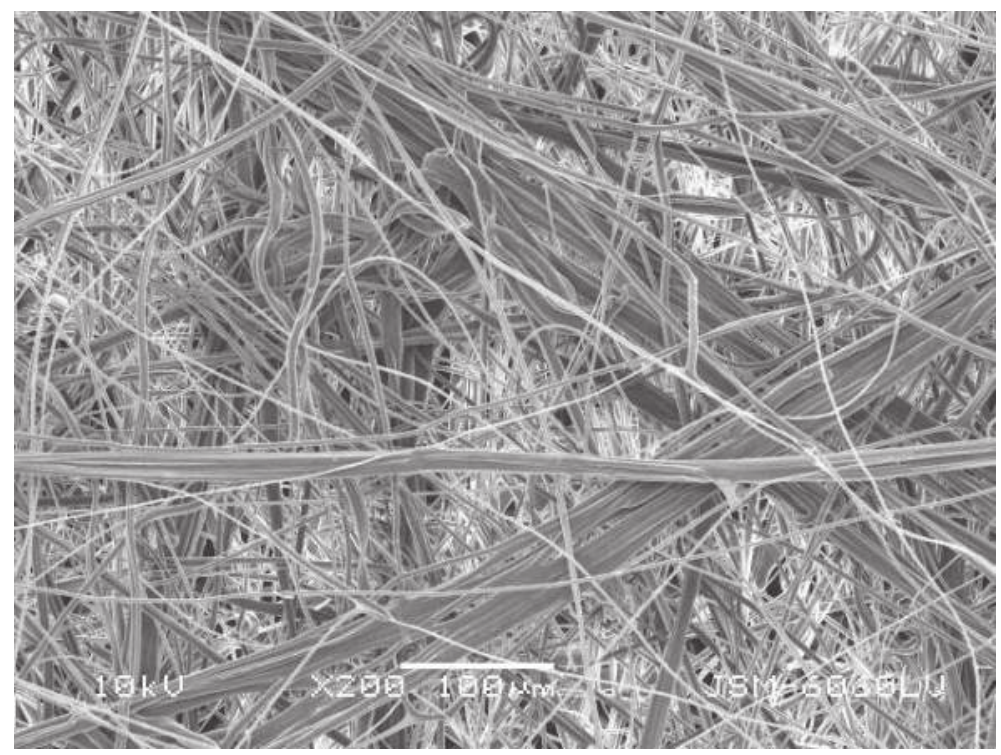

Fig. 2. The inner non-woven layer of the medical mask zoomed 200 times

The mask porosity parameters are presented in table 5 . Number of the pores on $1 \mathrm{~cm}^{2}$ is 45294 . The maximal diameter of pores is $30 \mu \mathrm{m}$. The open area (free for air flow) is $(8.42 \%$. The coefficient $a$ (regression equation 2 - flow air through dry sample), is 0.0921 . The exponent $b$ 


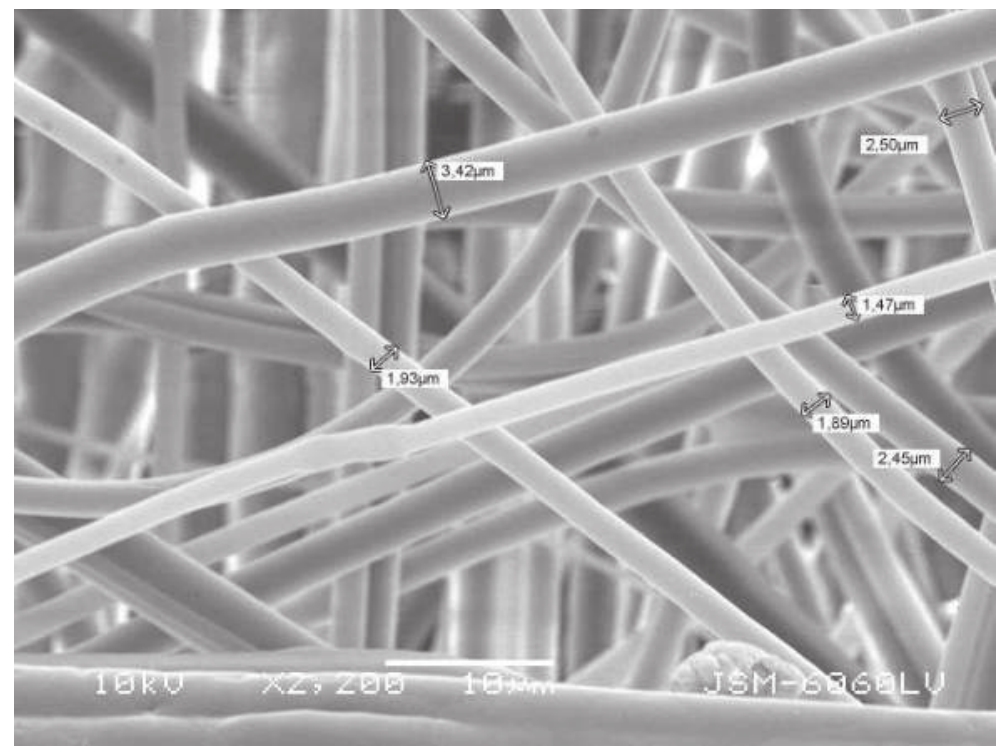

Fig. 3. The inner non-woven layer of the medical mask zoomed 2200 times

(regression equation 2 - flow air through dry sample) is 0.7521 . Mean hydraulic diameter of pores is $13.91 \mu \mathrm{m}$.

The nomenclature of table 5 is as following: $d_{\max }$ stands for the average pore diameter of the first interval (the largest pores), $d_{\min }$ stands for the average pore diameter of the last interval (the smallest pores), $d_{p}$ stands for the average pore diameter of the sample and $P$ stands for the average open hydraulic flow area. The pore distribution is presented in table 6.

\begin{tabular}{|c|c|c|c|c|c|}
\hline $\begin{array}{l}\text { Limits of the } \\
\text { classes }[\mu \mathrm{m}]\end{array}$ & $\begin{array}{l}\text { Hydraulic } \\
\text { diameter of } \\
\text { pores }[\mu \mathrm{m}]\end{array}$ & $\begin{array}{l}\text { Pressure } \\
{[\mathrm{Pa}]}\end{array}$ & $\begin{array}{l}\text { Volume } \\
\text { flow } \\
{\left[\mathrm{m}^{3} / \mathrm{s}\right] \cdot 10^{-6}}\end{array}$ & $\begin{array}{l}\text { Number } \\
\text { of pores }\end{array}$ & $\begin{array}{l}\text { Portion of } \\
\text { pores [\%] }\end{array}$ \\
\hline \hline $25-27$ & 26 & 3815 & 5.556 & 230 & 0.51 \\
\hline $23-25$ & 24 & 4133 & 13.100 & 329 & 0.73 \\
\hline $21-23$ & 22 & 4509 & 16.704 & 139 & 0.31 \\
\hline $19-21$ & 20 & 4959 & 66.931 & 2814 & 6.21 \\
\hline $17-19$ & 18 & 5510 & 120.306 & 3135 & 6.92 \\
\hline $15-17$ & 16 & 6199 & 233.431 & 6979 & 15.41 \\
\hline $13-15$ & 14 & 7089 & 323.569 & 6880 & 15.15 \\
\hline $11-13$ & 12 & 8266 & 516.463 & 16637 & 36.73 \\
\hline $9-11$ & 10 & 9919 & 652.269 & 8171 & 18.04 \\
\hline
\end{tabular}

Table 6. Parameters of porosity for mask (for all three non-woven layers) - number of pores according to the pore size intervals

\subsection{Influence of the mask layered structure on the filtration}

There are some differences in the functioning of the mask layers during its usage and during the porosity parameter measurement that had to be noted. As already noted, both outer layers 


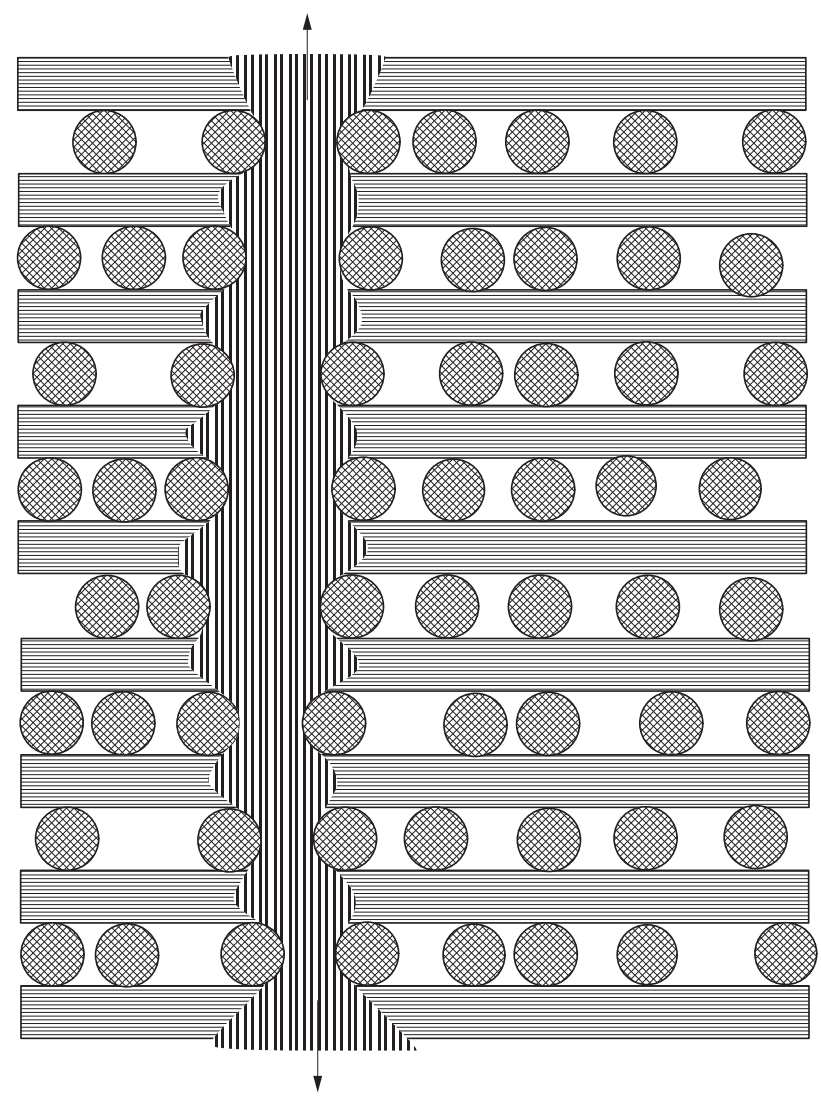

Fig. 4. Model of the stream of air through the non-woven mask due to the respiration

has smaller active surface due to their additional function to provide mechanical support for the inner layer.

The sample, which is undergoing the porosity test, is taken from the mask and placed in the apparatus head in exactly the same way. The area of the head is $1 \mathrm{~cm}^{2}$. The layers in the sample are pressed together during the test to avoid side leakage. This boundary effect affects relatively small area and may be neglected. True difference comes with the pressure at which the test is carried out. The test pressure at test compresses all three layers of a mask together. This effect obstructs free air passage beneath the areas of the outer layers that are 


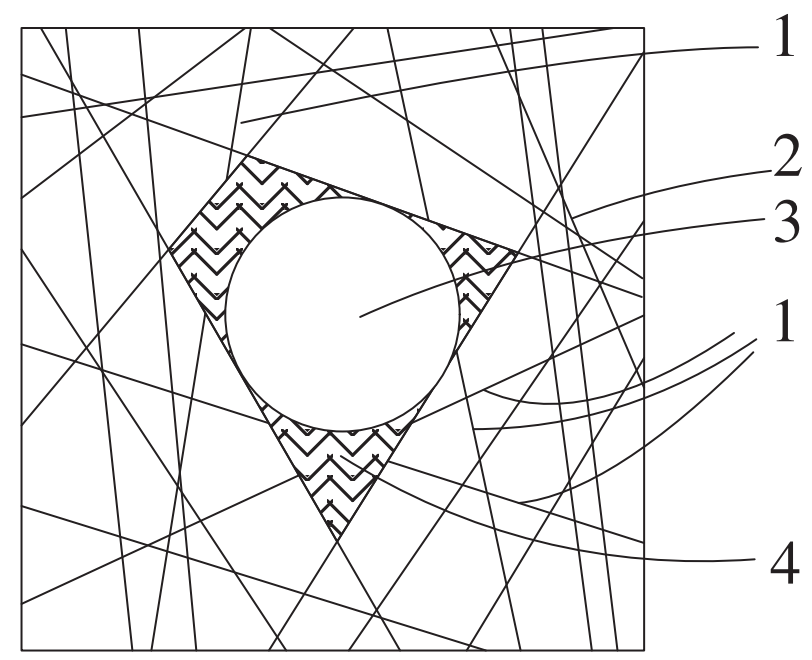

Fig. 5. Pore and a hydraulic pore of non-woven fabric. 1 - fibres that are narrowing the pore, 2 - fibre, 3 - hydraulic pore, 4 - a part of the pore where liquid has not been squeezed out during experiment of the J-method.

pressed together, which is not the case when a mask is used on a subjects face. In latter case all three mask layers are relatively loosely positioned together. The pressure caused by human breathing at supposed velocity of the air flow $(1 \mathrm{~m} / \mathrm{s})$ is so low $(20 \mathrm{~Pa})$ that it does not affect the position of a mask layer in respect to the others. As a consequence, the experimentally estimated open area may be underestimated.

The fluid flow rate, open area and fluid velocity are linked by equation (2) and the pressure (pressure difference between both sides of a mask) and air flow velocity are linked by equation (3). It is clear from these relations that if the same fluid flow rate is achieved in reality and at experiment, larger pressure inducing larger velocities would be needed at experiment, due to smaller open area, which is the consequence of mask layers being pressed together during the experiment.

The open surface was estimated to be $8.42 \%$ of the total active area. It has to be stressed that the estimate refers on the hydraulic area, defined by hydraulically active section of pores, see figure 5 , in interval down to pore hydraulic diameter of $8 \mu \mathrm{m}$. The limitation is due to the maximal pressure that can be achieved during experimentation and the capacity of the volume flow. The pore distribution presented in table 6 indicates that there may be a lot of pores smaller than $8 \mu \mathrm{m}$. These pores play an important role in filtration process due to relative proximity of the pore wall to the microbe or virus on one hand and they also let air through the mask. Due to latter we can assume that the open area is somewhat larger than estimated. 


\section{Classical filtration theory}

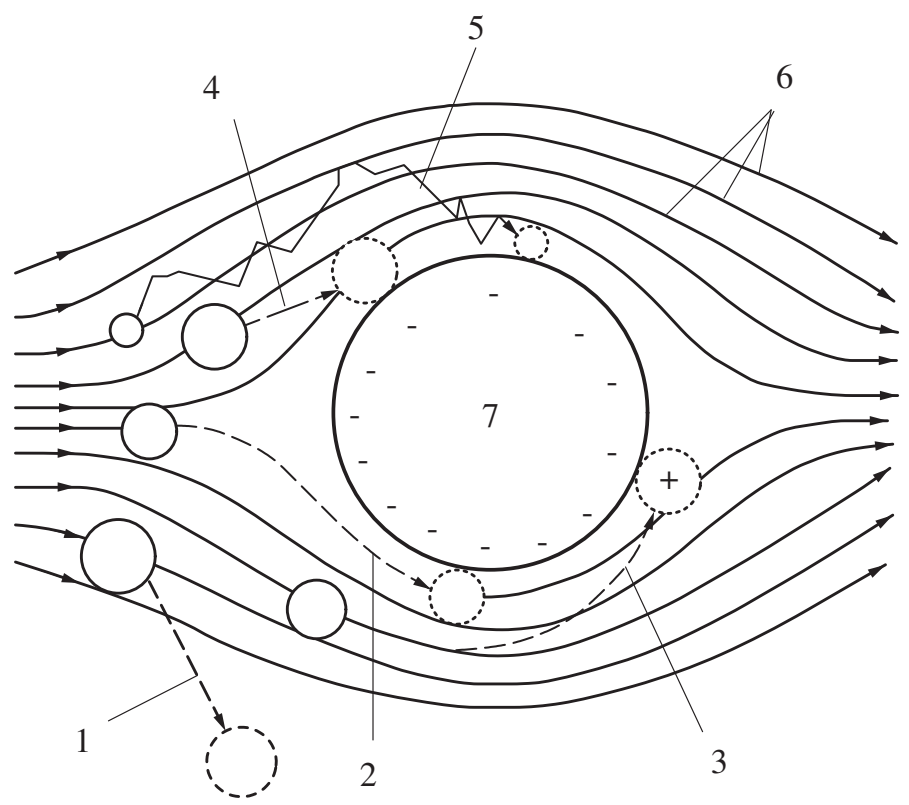

Fig. 6. Classical theory of the particles filtration on one fibre in the case of the laminar air flow: 1 - filtration of particles because of gravitation; 2 - filtration of the smaller particles on the surface of the fibres when they change their position from central part of the air flow to the virtual surface of the flow; 3 - electro filtration of the particles; 4 - filtration particles because of their steadiness; 5 - filtration very small particles by diffusion; 6 - air flow; 7 - fibre.

The classical filtration theory setting is presented in figure 6 - Sharma (2000), Brown (1993) and Hutten (2007), where a single fibre is put in the laminar fluid flow. The different sized particles are depicted with their supposed paths in order to depict different mechanisms of filtration. They are described in the following list:

1. The filtration due to gravitational field is applicable to largest and heaviest particles. This filtration mechanism can be observed in the outer fabric of the mask and does not apply to microbes and viruses.

2. The caption of a particle on a surface of the fibre due to its the collision with the fibre is generally applicable to the particles of all sizes. Unfortunately, the smaller the particle, the larger is the probability for the fluid flow to carry the particle pass the fibre due to the laminar nature of the air flow. The inertia of the particle in this case is negligible in comparison to fluid induced forces.

3. The electro filtration is a valid concept. However it is not applicable to the mask under consideration. 
4. The inertia of the particle may cause the particle to leave the streamline of the flow around the fibre and collide with it. In contrast with the point 2 the inertia of the particle is not negligible.

5. The presumption here is that the small particles (smaller than $1.5 \mu \mathrm{m}$ ) are moving by diffusion like paths as in the still air (Brownian motion) with one predominant direction in the direction of the fluid flow. We believe that this presumption is unjustified if the fabric porosity is taken into account.

\section{Novel approach to the filtration}

The classic theory of filtration is based on the flow around a single fibre. We argue that air is channelled through pores in the inner layer of the mask and hence, the modelling of filtration as a fluid flowing through a tube is justified. The justification is supported by the measurement of porosity parameters of the mask, which presumes the laminar flow through a sample Jakšić \& Jakšić (2007) and Jakšić \& Jakšić (2010).

\subsection{Nature of the air flow through a mask}

The nature of the fluid flow is described by Reynolds number, equation (6).

$$
\operatorname{Re}=\frac{\rho v d}{\mu}
$$

where $\rho$ stands for the fluid density, $v$ is the mean velocity of the object relative to the fluid, or vice versa, $d$ for the characteristic linear dimension (pore hydraulic diameter or particle diameter or fibre diameter) and $\mu$ for the dynamic viscosity of the fluid.

The value of the air density is $\rho=1.2 \mathrm{~kg} / \mathrm{m}^{3}$ and its dynamic viscosity $\mu=18 \mu \mathrm{Pa} \cdot \mathrm{s}$. The characteristic linear dimension is defined according to the object of interest. If the flow through a pore is studied, the dimension is its hydraulic diameter. On the other hand, if the flow around stationary particle is in question, the dimension is its diameter.

The velocity of the fluid (air) through a mask can be deduced from mask's porosity parameters and human physiology. The air velocity at inhaling or exhaling depends on breathing intensity. Latter depends on an activity and the intensity of the activity of the mask user. The exhaled air is normally denser than inhaled one due to its increased humidity. Let's suppose that a subject inhales from 12 litres of air per minute at normal pressure and during light activity and $60 \mathrm{l} / \mathrm{min}$ during moderate exercise. Further on, suppose that the subject inhales 12 times per minute. The size of the active surface of the mask inner layer is $160 \mathrm{~cm}^{2}$, and the open area of the layer is $8.42 \%$ of the active surface, table 4 . The open area is thus $13.5 \mathrm{~cm}^{2}$. The air flow velocity through mask inner layer is thus approximately $0.17 \mathrm{~m} / \mathrm{s}$ during light activity and $0.86 \mathrm{~m} / \mathrm{s}$ during moderate exercise Zuurbier et al. (2009). As a conservative approach the value of $1 \mathrm{~m} / \mathrm{s}$ is taken in order to compute Re number.

The maximal pore hydraulic diameter is $30 \mathrm{~m}$, table 4 . The Reynolds number for fluid flow through the largest pore is $\operatorname{Re}=2<<2300$, which ensures laminar air flow through the inner mask layer.

The mask is designed to filter all viruses, which come in different sizes: from 10nm to 300nm. When inhaling (or exhaling) the air starts to flow, but a virus is not following instantaneously. The Reynolds number at the moment when a virus is stationary and the air is already moving 
is computed with maximal air velocity, even though that the virus is picked up by the air flow, to stay at conservative approach. In this case the $R e=0.02<<0.1$, the limit for the laminar flow around the object in the fluid flow is much stricter than the one for the flow in a tube.

We can conclude that the filtration in the inner mask layer is done in the laminar air flow.

\subsection{Determination of the physical domain of the problem}

The process of filtration that is carrying out in the medical masks is at the micro and nano scale. The size of the pores of the mask inner layer is at the micrometer scale and the size of viruses is at the nanometer scale. The Kundsen number $(K n)$ is used to determine whether the classical mechanics of continuum is still valid approach. Kundsen number is defined as

$$
K n=\frac{k_{B} T}{\sqrt{2} \pi \sigma^{2} p L}
$$

where $k_{B}$ stands for the Boltzmann constant, $T$ for the thermodynamic temperature, $\sigma$ for the particle hard shell diameter and $p$ for the total pressure and finally $L$ for the representative physical length scale. The value of $K n$ for maximal pore and virus size is $K n \approx 10^{-9}$, which is much less than 1 . Hence, the mechanics of continuum is applicable.

\subsection{Numerical modelling of the virus behaviour in the straight pore}

In addition to the mechanisms of filtration described by the classical filtration theory the filtration caused by laminar flow through pores is described. A pore in the mask inner layer is approximated by a tube or a channel. The inner layer is formed in complicated way - it is composed of 37 sub-layers. Each of these sub-layers is composed of fibres randomly placed in random direction, making a pore meandering through all sub-layers a complex path for air to take, see figure 4 . We can suppose that:

1. A pore changes its direction 35 times, when leaving on sub-layer and enters the other.

2. The change of the direction is random.

3. At the direction change the pore may split. Nevertheless, during the experiment for determining porosity parameters, we have actually taken into account these newly formed pores.

4. The length of a pore is at least twice the width of the inner layer, which means that the length of the pore is at least $570 \mu \mathrm{m}$, together with both outer layers.

5. Estimated pore diameter in the experiment is the smallest diameter of the pore over a whole width of the mask. Hence, the pore is acting as a tube or a channel.

6. The particle can be filtered on the obstacle (classical filtering theory) or in a void after the obstacle or at the pore's wall.

Based on the presumptions about shape of the pore the simple numerical model was built in order to show different possibilities of filtration and to asses some postulates of the classical filtration theory. The shape of a virus is idealised with the sphere/circle.

A simple 2D computational fluid dynamics (CFD) model was used for the simulation purposes of the virus behaviour in the laminar fluid flow in straight tube as a first 
approximation. A virus, represented by a circle, is placed in a rectangular, which is representing 2D model of a tube (pore), figure 7. The top and bottom walls are defined as no-slip wall where fluid velocity is zero due to the surface roughness. The virus boundary is defined in roughly the same way. The radial velocity of the fluid at the virus boundary is zero (no fluid penetration is allowed) and the circumference fluid velocity at the virus boundary is set to an arbitrary value to simulate possible virus rotation. The initial velocity with the uniform profile is prescribed at the inlet (left tube boundary) and the environment pressure is prescribed at the outlet (right tube boundary), figure 7 . The results of the laminar model obtained with our target solver (ANSYS-FLUENT) were checked with the results of the turbulent model of the same solver and with the laminar model results of the 3D model in ANSYS-CFX solver. The results of the different models/solvers were in the excellent agreement and we proceeded with the 2D laminar modelling in ANSYS-FLUENT solver.

The aim the numerical modelling is gaining a qualitative picture of the mechanical system that is governing the particle flow through a medical mask. On this base the mesh of the model was relatively course, figure 8 . The boundary layer at the tube walls were not in focus of this analysis and so the free meshing was used at whole region. The virus surroundings are meshed with the structured mesh with the smallest elements at the virus surface.

The tube diameter is $30 \mu \mathrm{m}$, which correspond to the maximal pore hydraulic diameter. The length of the tube is $120 \mu \mathrm{m}$, which is enough for the complete laminar velocity profile formation before striking the virus in the middle of the tube, figure 9 . The laminar velocity profile, equation (8), was established approximately one tube diameter from the inlet.

$$
v(r)=\frac{3}{2} v_{o}\left(1-\frac{r^{2}}{R^{2}}\right)
$$

where $v_{0}$ stands for the initial velocity at the inlet, $r$ for the radius of the streamline and $R$ for the radius of the tube Widden (1966). The maximal velocity is $v_{m}=1.5 v_{0}$.

\subsubsection{Fluid induced motion of the particle in the axial direction}

The fluid induced force was estimated for the stationary virus at the centre of the tube cross-section $(r=0 \mu \mathrm{m})$ for different initial velocities as a function of the maximal flow velocity. The circumferential velocity of the fluid at the virus surface is set to zero value no virus rotation allowed. The fluid induced force is actually the driving force in this case, since the fluid is moving and the virus is stationary. It was found out that the fluid induced force $F_{a}$ scales linearly with the fluid velocity $v_{m}$.

$$
F_{a}=C v_{m}
$$

where $C$ stands for the constant that depends on the virus size. $C_{300}=4.8 \cdot 10^{-12} \mathrm{Ns} / \mathrm{m}$ for the maximal virus size of $300 \mathrm{~nm}$, figure 10 , and $C_{10}=32.5 \cdot 10^{-15} \mathrm{Ns} / \mathrm{m}$ for the minimal virus size of $10 \mathrm{~nm}$. It is obvious that the forces acting on a virus are extremely small even if the virus is kept stationary.

If the virus is not stationary, the velocity $v_{m}$ in equation (9) represents the difference of the velocity of the fluid flow and the virus. The second Newton law is used to compute virus velocity in the axial direction.

$$
C\left(v_{m}-v\right)=m \frac{\mathrm{d} v}{\mathrm{~d} t}
$$




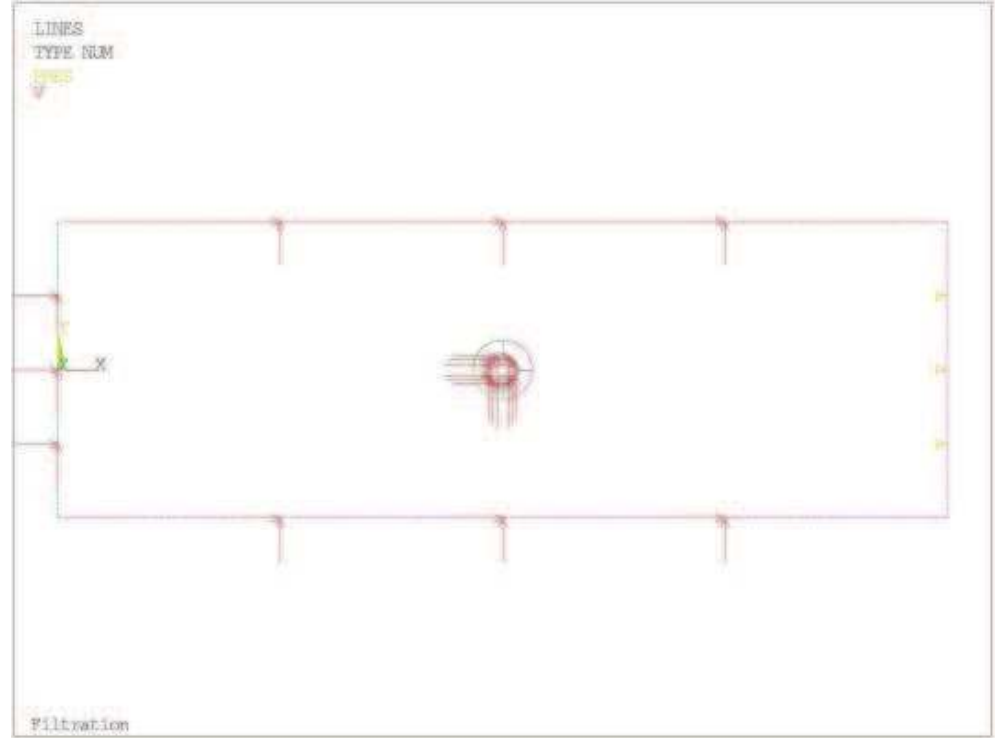

Fig. 7. 2D model of the virus in the pore. The size of the largest virus is magnified 10 times here for the presentation purpose only.

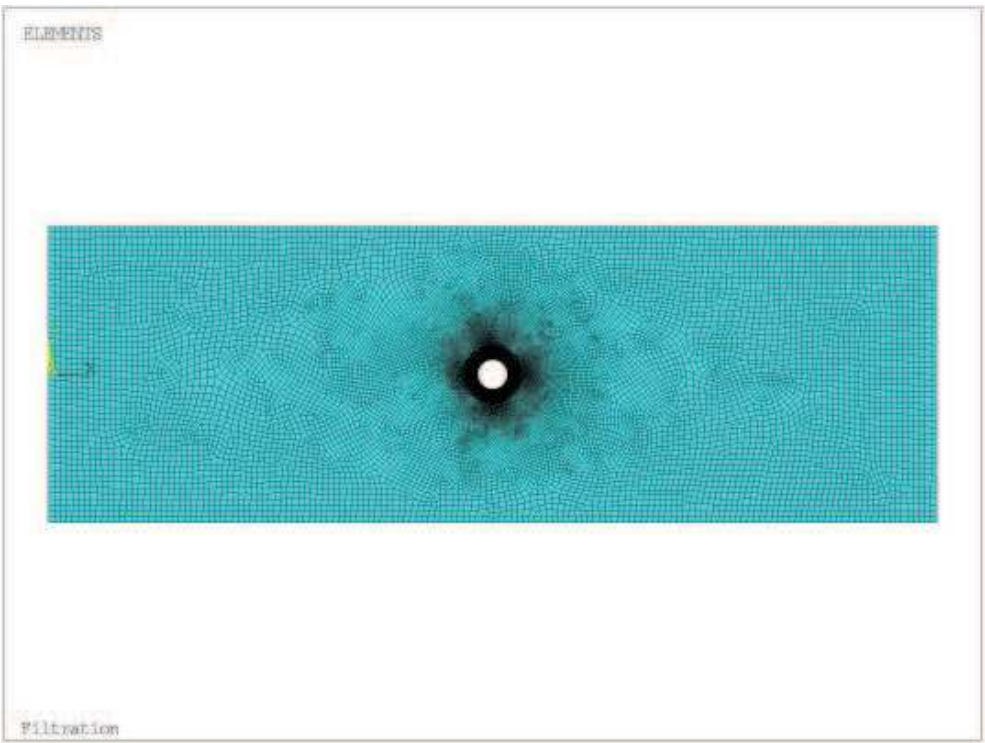

Fig. 8. CFD mesh. The size of the largest virus is magnified 10 times here for the presentation purpose only. 


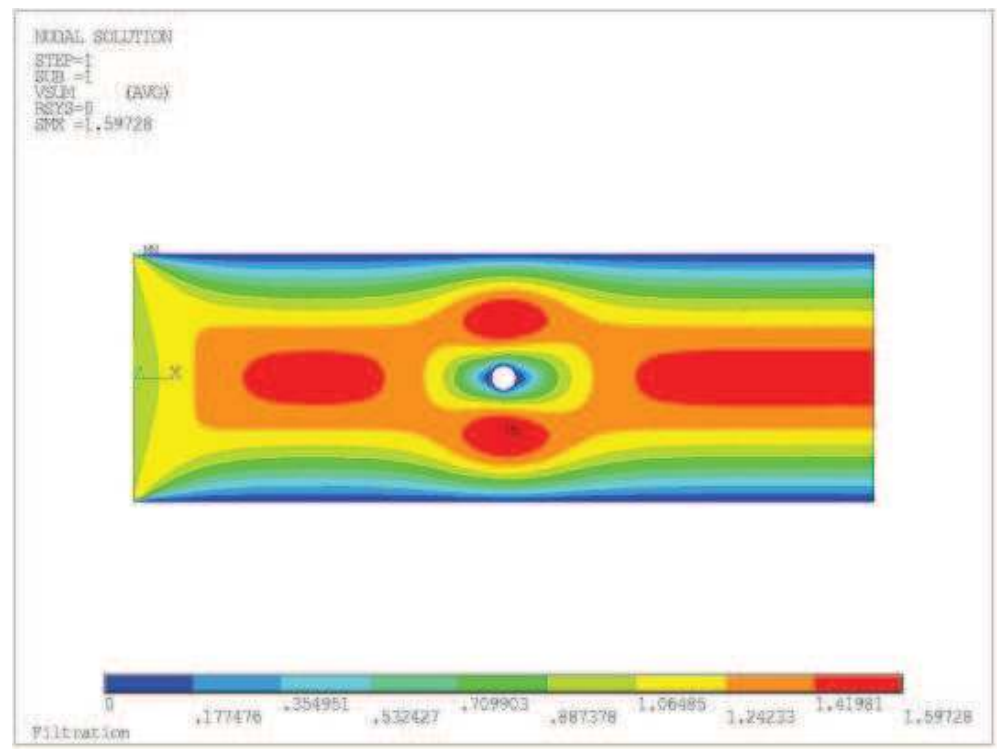

Fig. 9. Velocity contours. The size of the largest virus is magnified 10 times here for the presentation purpose only.

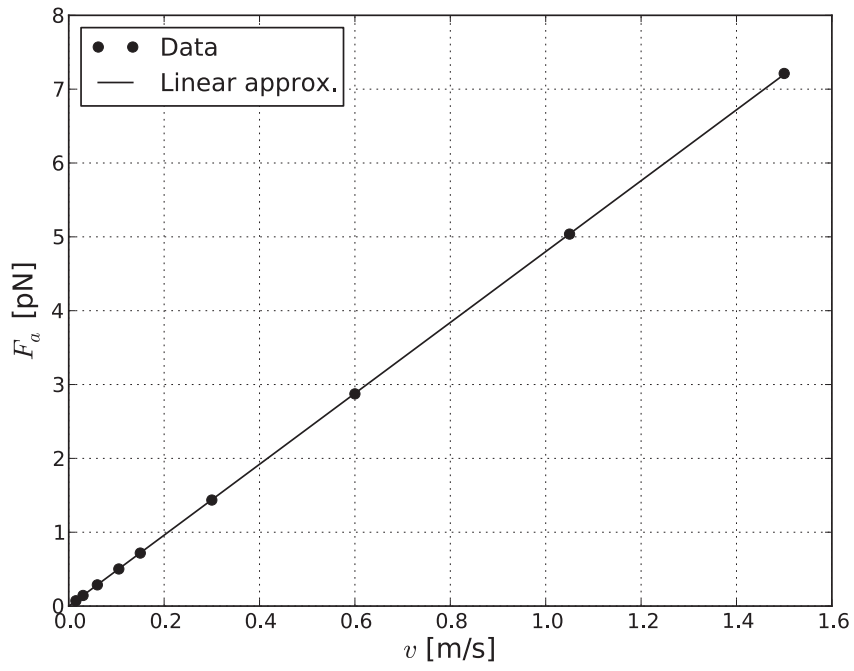

Fig. 10. The fluid induced force on a larger virus. 


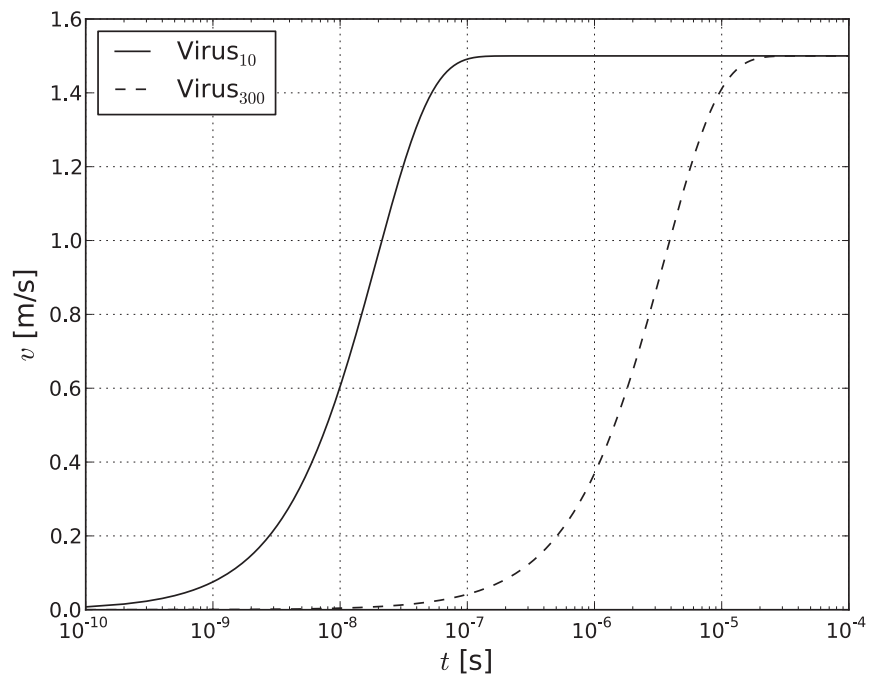

Fig. 11. The virus velocity as a function of time.

where $v$ stands for the virus velocity and $m$ for its mass. The mass of the virus of the maximal size can be estimated to $m_{300}=17.0 \cdot 10^{-18} \mathrm{~kg}$ and the mass for the smallest can be estimated to $m_{10}=0.63 \cdot 10^{-21} \mathrm{~kg}$. Equation (10) can be resolved analytically and the results are presented in figure 11 .

$$
v(t)=v_{m}\left(1-e^{-\frac{c}{m} t}\right)
$$

Further on, the axial displacement of the virus can be computed by integrating the equation (11) once again.

$$
x(t)=v_{m}\left(t+\frac{m}{C}\left(e^{-\frac{c}{m} t}-1\right)\right)
$$

The smaller virus reaches $99 \%$ of the fluid velocity in $8.9 \cdot 10^{-8} \mathrm{~s}$ and $99.9 \%$ in $1.3 \cdot 10^{-7} \mathrm{~s}$. The larger virus's inertia is larger and so does the time. The $99 \%$ of the fluid flow is reached in $1.6 \cdot 10^{-5} \mathrm{~s}$ and $99.9 \%$ in $2.4 \cdot 10^{-5} \mathrm{~s}$.

\subsubsection{Fluid induced motion of the particle in the radial direction}

It might appear that the predominant direction of motion is in the axial direction since the forces acting on a absolutely stationary virus in the perpendicular direction to the fluid flow are much smaller. The analysis providing us with the axial force on a stationary virus provides us also with the radial one. There is no radial force if the virus is placed in the tube centreline, due to the symmetry. If the stationary virus is moved towards the tube top boundary, the radial force is pointing towards the tube centreline. The same is true if the stationary virus is moved towards bottom tube boundary. The radial forces are at least one order of the magnitude smaller than the axial ones depending on the virus position. It appears that the largest radial force relative to the axial one can be found at roughly $\frac{1}{4}$ of the tube diameter from the top or bottom boundary. 
So far the numerical results showed that the filtering in the straight tube is not possible because the stationary viruses are forced toward the fluid flow centreline. A look at moments acting on the virus reveals that the moment (torque) is present due to fluid viscosity. The torque is acting in the negative ( $\mathrm{CW}$ - clock wise) direction if the virus is placed between the centreline and top boundary and in the positive (CCW - counter clock wise) direction if the virus is placed between the centreline and bottom tube boundary, figure 18. The virus is actually free to rotate and the redial force changes its direction towards tube boundaries, figure 14, due to the Magnus effect. The model shows this phenomenon, figure 14, and hence the filtering is possible even if the tube is perfectly straight.

The natural way of causes and consequences tells us that the moment drives the virus's rotation. The model is set in a way to address this phenomenon in the inverse approach. The circumferential velocity of the virus is prescribed as boundary condition for the fluid and the moment acting on the virus is estimated in the analysis. The results for the large virus placed at $\frac{1}{4}$ of the tube diameter from the top boundary, figure 12 .

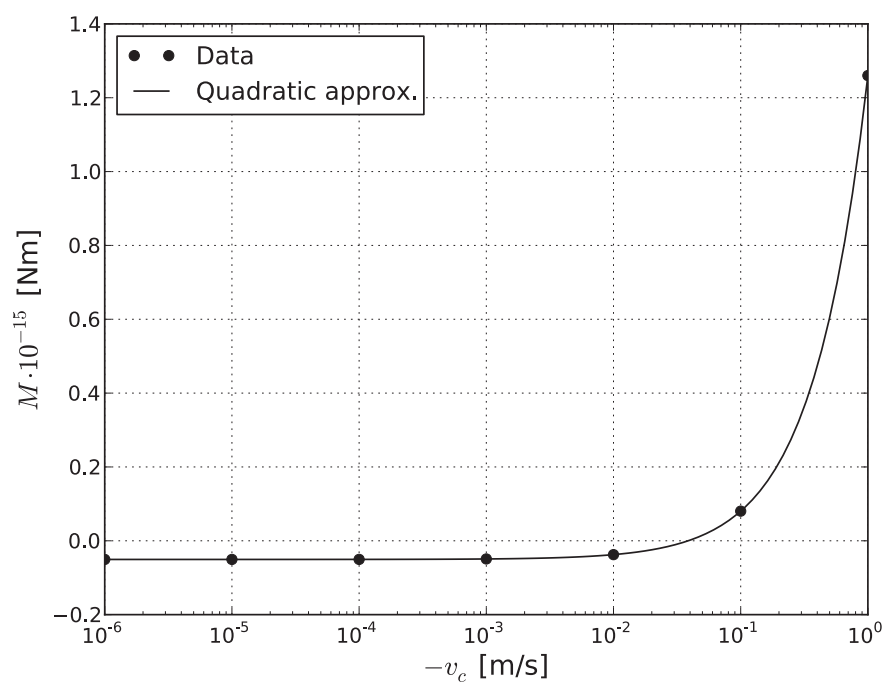

Fig. 12. The fluid induced moment acting on large virus as a function of the virus rotation.

The moment is at first negative and quite constant. It increases with the increasing circumferential velocity of the virus. It is obvious that it cannot reach the positive value at high circumferential velocities, due to the simple fact that the moment is driving the virus rotation and the change in the moment sign indicates, that the fluid flow, that generates the moment and was previously acceleration the rotation, is slowing down the virus rotation in such a case. The expectation is that the virus will rotate with the constant angular velocity, which value is defined by the zero moment. The moment is approximated with the polynomial of the second order, equation (13), as presented in figure 12.

$$
M(\omega)=a \omega^{2}+b \omega+c
$$


where $M$ stands for the fluid induced moment acting on virus, $\omega$ for the angular velocity of the virus and $a, b, c$ for the approximation parameters. The second Newton's low for rotation of the rigid body is used to generate the equation of motion for the virus rotation.

$$
\frac{\mathrm{d} \omega}{\mathrm{d} t}=\frac{M(\omega)}{J}=A \omega^{2}+B \omega+C
$$

where $J$ stands for the virus moment of inertia and $A, B, C$ for the approximation parameters divided by $J$. The moment of inertia $J$ of the largest virus is $1.53 \cdot 10^{-31} \mathrm{kgm}^{2}$ and for the smallest is $6.3 \cdot 10^{-39} \mathrm{kgm}^{2}$. Equation (14) can be resolved analytically.

$$
\omega(t)=\frac{D}{2 A} \tanh \left(\operatorname{arctanh}\left(\frac{B}{D}\right)-t \frac{D}{2}\right)-\frac{B}{2 A}
$$

where $t$ stands for time, $A, B, C$ for the approximation parameters divided by $J$ and $D$ for the discriminate, $D=\sqrt{B^{2}-4 A C}$. The virus terminal angular velocity is reached in the limit case $t \rightarrow \infty$ as

$$
\omega_{\max }=\frac{-D-B}{2 A}
$$

The terminal circumferential velocity is computed as $v_{\mathcal{C}_{\max }}=\omega_{\max } R$, where $R$ stands for the virus radius. The values of the terminal (maximal) circumferential velocity for the larger virus is $v_{\mathcal{c}_{\max }}=-0.0386 \mathrm{~m} / \mathrm{s}$ and for the smaller one $v_{\mathcal{c}_{\max }}=-0.0146 \mathrm{~m} / \mathrm{s}$ which is around $4 \%$ and $1.5 \%$ respectively of the air velocity at the inlet. What is really important is that viruses begins to rotate with the terminal angular velocity in a very short time, almost instantly, see figure 13.

The radial force was computed and approximated in the same way as the moment, see figure 12. Hence, by combining it with the angular velocity, the radial force can be plotted as function of time, figure 14. The force becomes constant with the virus reaching the terminal angular velocity.

Although figure 14 presents the resultant force, we can say that there are two competing mechanisms of delivering the radial driving force to the virus. It has been stated that the virus is driven towards the tube centre if it does not rotate due to the fluid flow velocity profile. The same velocity profile also drives the rotation of the virus which in turn adds radial force (Magnus effect, where the rotation is self induced - we named it as J-effect) in the direction of the tube/channel boundary. If the rotation is large enough, which is the case here, the radial force due to the rotation is larger than one due to the fluid profile. The force partition described here is a simplification of a complex fluid velocity and pressure distribution in the vicinity of a virus and serves only as an intuitive description of the physical behaviour due to the fact that an object in the tube/channel distorts the fluid flow profile and the way that fluid flows around a virus.

The analysis were repeated for other virus initial positions - position at $\frac{1}{8}$ of the tube diameter from the top boundary and for position at $\frac{3}{8}$ of the tube diameter from the top boundary. The terminal radial forces are presented with dots for both viruses in figures 15 and 16 together with their quadratic approximations, equation (17).

$$
F_{r}(y)=a y^{2}+b y+c
$$




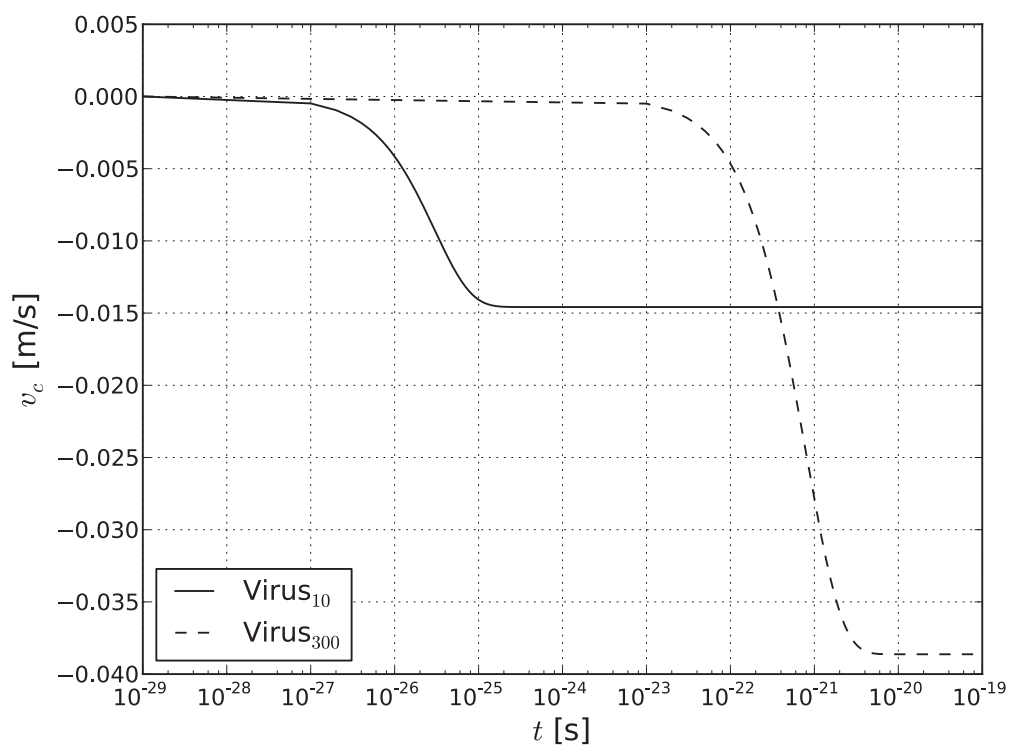

Fig. 13. The virus circumferential velocity as a function of time.

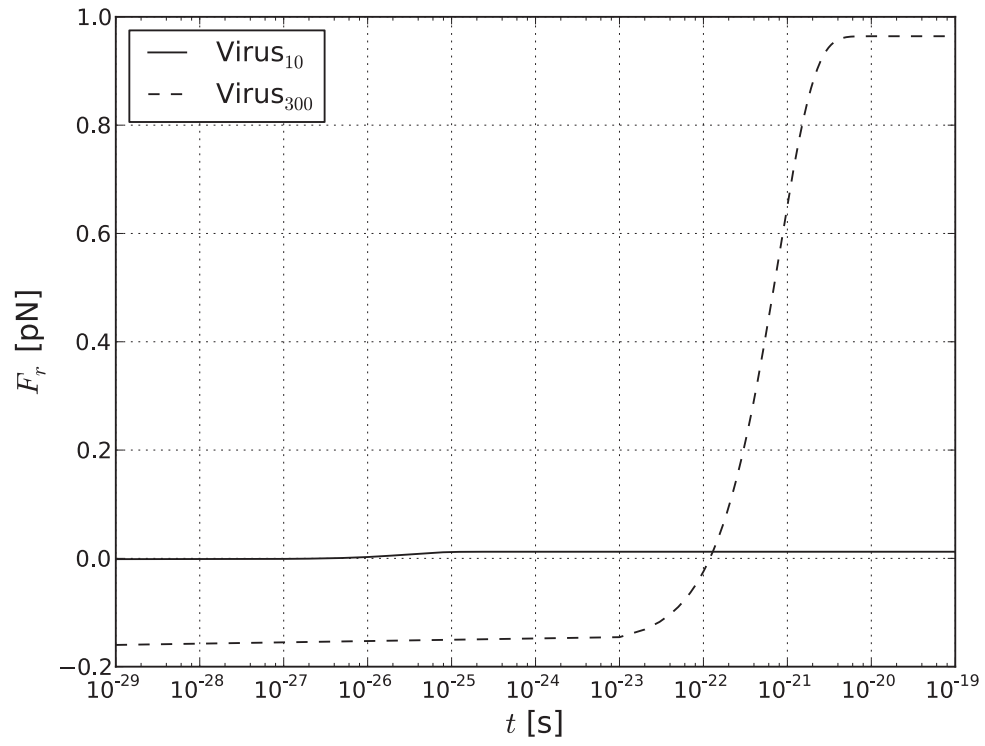

Fig. 14. The radial force as a function of time. 


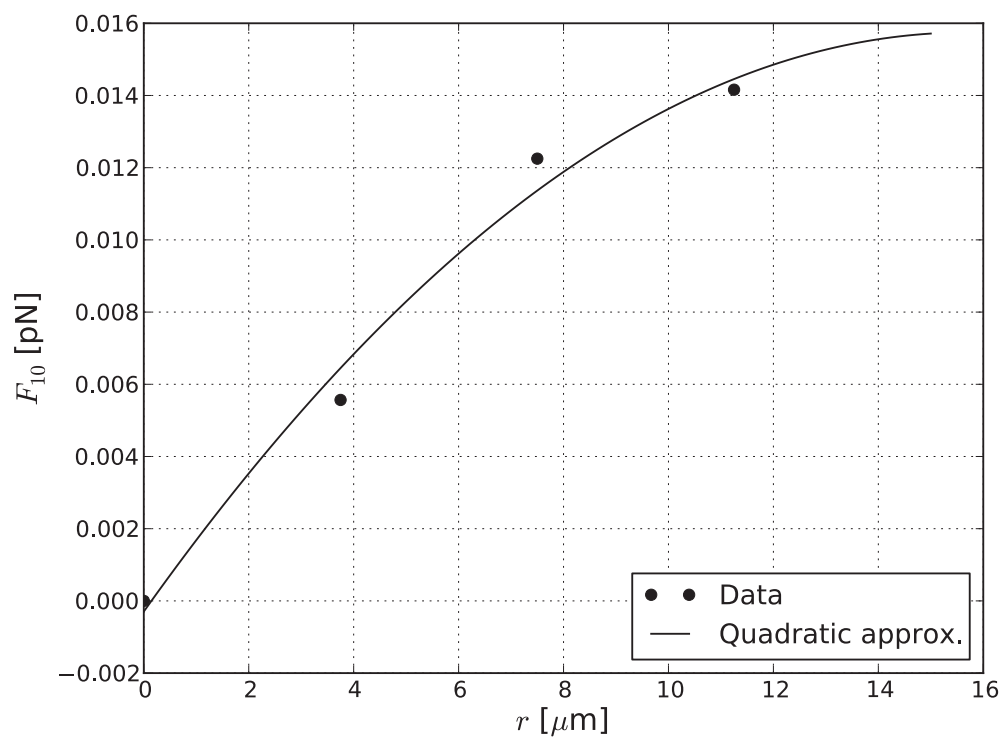

Fig. 15. The radial force at virus positions form the centreline up for the small virus.

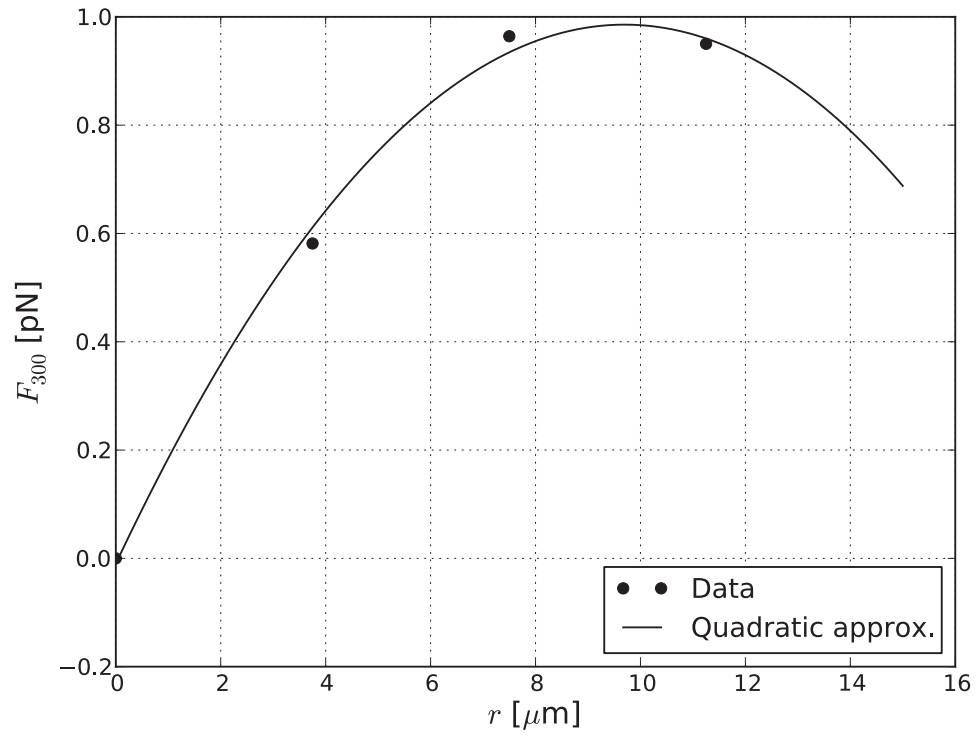

Fig. 16. The radial force at virus positions form the centreline up for the large virus. 
where $F_{r}$ stands for the radial force on virus, $y$ for the virus displacement in the radial direction and $a, b, c$ for the approximation parameters. This data is used to compute the virus kinematics in the radial direction. The second Newton's law was used again.

$$
\frac{\mathrm{d}^{2} y}{\mathrm{~d} t^{2}}=\frac{F_{r}(y)}{m}=A y^{2}+B y+C
$$

where $m$ stands for the virus mass and $A, B, C$ for the approximation parameters divided by $m$. The equation can be solved analytically. Nevertheless, the solution is awkward to use and the numerical integration of the differential equation (18) presented in figure 17 was used.

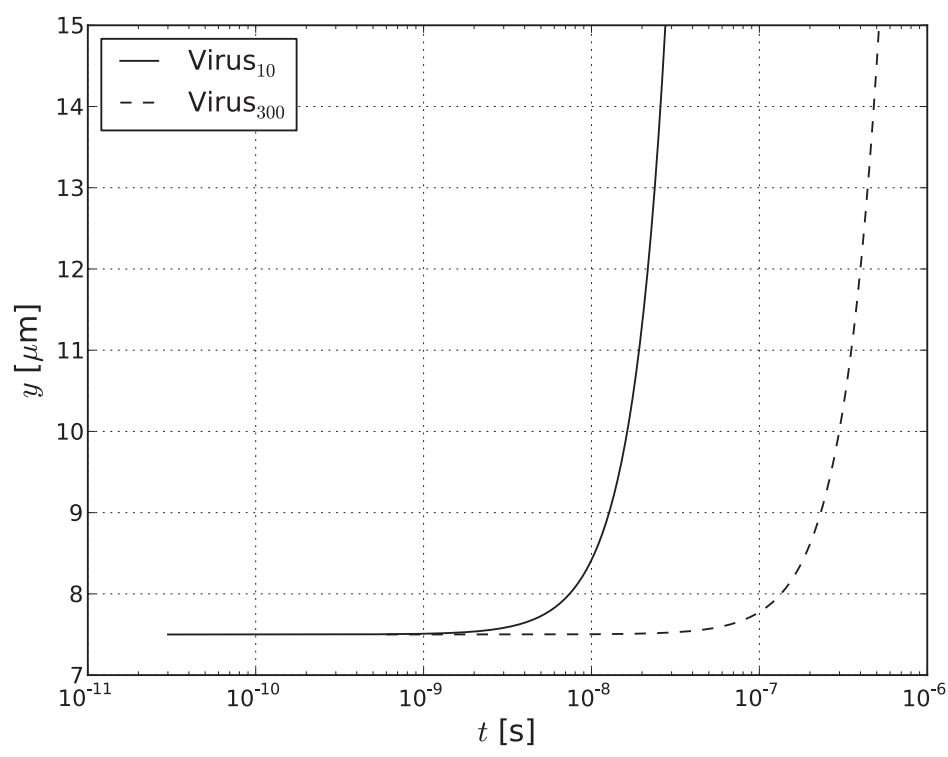

Fig. 17. The radial virus path.

It is interesting to compare figures 11 and 17. We can conclude for the larger virus that it is captured by the tube wall in $5.1 \cdot 10^{-7} \mathrm{~S}$ and for the smaller virus that its capturing time is approximately $2.7 \cdot 10^{-8} \mathrm{~s}$. The axial velocity of the larger virus at the capture time is only $0.15 \mathrm{~m} / \mathrm{s}$, which is about $10 \%$ of its maximal axial velocity and its axial displacement is approximately $4.0 \cdot 10^{-8} \mathrm{~m}$, which is three orders of the magnitude less than its displacement in the radial direction. The picture is somewhat different with the smaller virus. It reaches $0.85 \mathrm{~m} / \mathrm{s}$, which is already about $57 \%$ of its maximal axial velocity. It travels approximately $1.4 \cdot 10^{-8} \mathrm{~m}$ in the axial direction, which is again three orders of the magnitude less than its displacement in the radial direction.

The mechanism of filtration presented here, which is based on fluid induced rotation of a round object, is closely tied to the Magnus effect. It is valid also in the case of the curved tube, due to the laminar nature of the fluid flow. Hence it is an efficient way of filtration of viruses and microbes. 


\subsection{Criticism of the classical theory of filtration}

The fluid flow that flows around a single fibre is the base upon the classical filtration theory is built, as presented in figure 6 . The flow is divided by the fibre and the steam lines that are curved around the fibre, get together again behind the fibre.

The situation, described by the classical filtration theory, is actually occurring during the air flow through the mask. However, the amount of air experiencing it is much smaller than the amount of air that is flowing through pores; see figures 2, 3 and 4, particularly due to the reason that the porosity measurement takes into account split pores.

The shortcomings of the classical filtration theory can be summarized as follows:

1. The fibres have a role of the pore boundary at non-woven fabrics. There are caverns in between the fibres where the air does not flow, see figure 5. The virtual surface is formed between the fluid flow and the void when fluid is in motion. The pore caverns, where there is never a significant air flow, are not explained by the classical filtration theory.

2. The classical filtration theory foresees the Brownian motion with one predominant direction, see figure 6 , for particles smaller than $0.15 \mu \mathrm{m}$. Such particles supposedly hit the fibre by being thrown out of the flow by the diffusion mechanism. They may be forced by a collision with a larger particle or supposedly by air molecules. The mechanism of the collision with the larger particle is feasible. On the contrary, the model of the mechanics of continuum does not support a mechanism of filtration based on the Brownian motion of the small particle in the fluid flow. The Brownian motion of the small particles plays an important role in the caverns, where there is predominantly still air.

3. The classical filtration theory considers the diameter of a fibre as the only characteristic linear measure when computing the Reynolds number. It has been shown that, if the maximal pore diameter is taken into account, the Reynolds number is the order of the magnitude larger. The Reynolds number for the flow around an object in the flow is much smaller, but the limit where turbulent flow starts is also much smaller than in the case of the flow in a tube.

\subsection{Mechanisms of filtration of the medical masks}

The main difference between the classical filtration theory and the theory presented here is that the air flowing through the medical mask is supposed to flow through channels. This claim is supported by the theoretical and experimental findings of the J-method for the flat textile porosity assessment. The laminar flow through a channel (or a tube) establishes parabolic fluid flow velocity profile. The velocity profile enables the self-induced rotation of the spherical or near-spherical particles. The angular velocity reaches its limit value almost instantly causing the radial force to point towards the channel boundary due to the Magnus effect. Thus, the effective filtering is enabled and the whole phenomenon is named as the J-effect.

Based on the developed theory, numerical simulations and observations of the filtration of the industry waste gases, where needled flat textile is used, the mechanisms of filtration can be summarized in following points.

1. The particle, which is positioned at the centerline of the channel (tube), stays there until it collides with another particle or until the channel changes the direction. 
2. When the particle is captured by the fiber surface or is separated from the flow into a cavern, then its kinetic energy is too low for the particle to be sucked into the flow again.

3. The particle, which velocity is lagging from the flow one, does not exhibit Brownian motion.

4. Small particles, which are positioned in the caverns, exhibit Brownian motion and are filtered out by being captured at the fibers' surfaces at the caverns' boundaries in the process of diffusion.

5. The volume of the caverns and the channels become an unified space during the undisturbed period between the inhalation and exhalation. Thus the viruses can move freely between the caverns and channels.

6. The particles having spherical or near-spherical shape starts to rotate, if they are not placed at the channel centre.

7. The particle rotation is caused by the velocity-pressure distribution around the particle surface which is the consequence of the parabolic velocity profile (J-effect). The angular velocity of the particle reaches stationary value almost instantly and this triggers the radial force that is driving the particle towards the channel boundary (Magnus effect). The main difference with the normal comprehension of the Magnus effect is that the rotation of the virus is of the endogenous origin (self-induced) and not of the exogenous one (J-effect).

8. The particles that have not been filtered during the inhalation or have migrated from the caverns to the channels during the undisturbed period, will, during the exhalation, behave in the same way as they would during the inhalation. Only the direction of the fluid flow changes.

9. The air flow through a channel is at least partly accelerated and decelerated by breathing of a subject which enhance the fluid induced forces acting on a virus. Only stationary state has been taken into account at the analytical/numerical analyses.

10. The channel configuration is complex, changing its direction and diameter many times. The geometry of the channel is not known to us except for its minimal diameter, which is identified by the J-method.

11. The cylindrical (helical) viruses generally do not rotate. The probability for them to be positioned in the channel just right to enable J-effect is extremely small. Hence, this viruses are difficult to filter in a straight channel (tube). Their size is normally much larger than $10 \mathrm{~nm}$ and their inertia plays an important role at filtering those viruses at the channel's bends.

12. Except for the criticism expressed in this text, the mechanisms of the classical filtration theory still applies and they are not discussed further.

This analysis was limited to a straight channel (tube) and perfectly spherical virus, see figures $7-9$ and figure 18. We have also established, that the channel length is large enough to support the stationary fluid flow. There are more parameters that affects the complex process of filtration. Some of them are difficult to assess, some are left aside to show the basic mechanism of filtration of the spherical or near-spherical particles in a medical mask. The interesting parameters that influence the filtration process are:

1. the concentration of the particles,

2. the particle interactions, 
3. the size distribution of the particles,

4. the different shape of the particle,

5. the different thicknesses of the sub-layers of the mask filtering layer,

6. the thickness of the fibres,

7. the fibres' cross-section,

8. the maximal hydraulic pore diameter and the pore distribution,

9. the size of the caverns and

10. the breathing pattern as a function of a subject condition.

\subsection{Illustration of the mechanisms of filtration of the medical masks}

The virus behaviour of filtration (J-effect) is depicted in figure 18. If a virus is placed at the channel centerline, then the distribution of the fluid velocity and pressure around the virus is symmetrical, no virus rotation and consequently no radial force is present. The virus B stays on the centerline. Such a virus can be filtered at the channels' bends or if it is thrown out by a collision with another particle.

The virus A (or C) does not rotate at first and the radial force drives it toward the centerline, figure 18 (I). When the virus begins to rotate and this happens almost instantly and the direction of the radial force changes toward the channel boundary, figure 18 (II). It has to be stressed here that the velocity profile changes locally at the virus location and the parabolic profile is locally lost.

The process of filtration during and between the inhalation and the exhalation is shown in figures 19 - 21, where denotations are: A - cross-section, B - view along the channel, 1,2,3,4 -

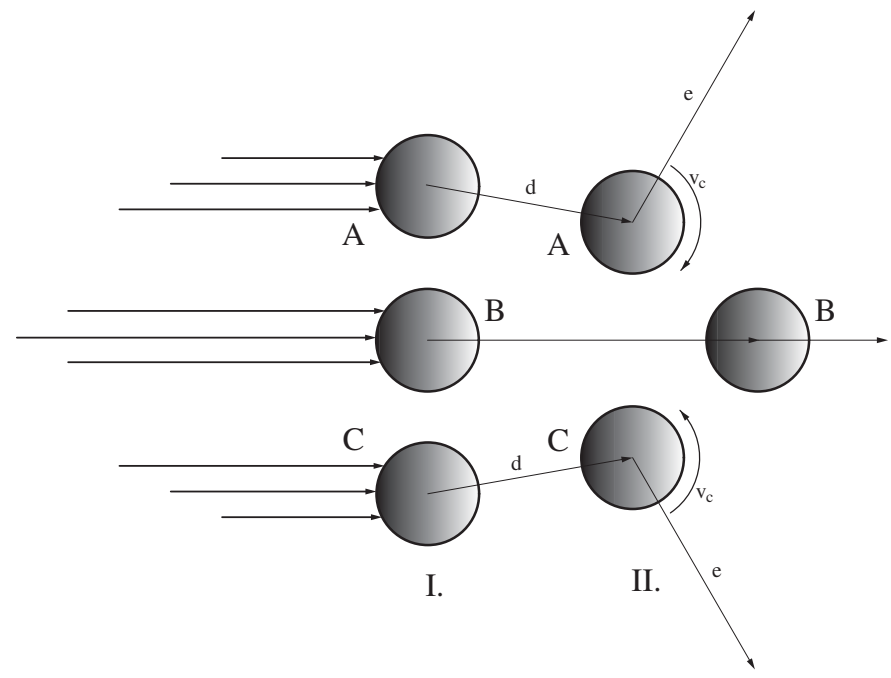

Fig. 18. Illustration of a virus in the fluid flow in a channel. 
fibre, 5 - particle, that has been captured by a fibre surface, 6 - particle, that has been separated into a cavern, 7 - streamline, 8 - airflow velocity profile, 9 - mouth of the mask user.

The filtration process during inhalation is shown in figure 19. There are five particles shown at the entrance of the channel, one of them is placed at the channel centreline (position at the beginning). This virus travels the fastest in the axial direction due to the airflow velocity profile. The other viruses travels also into the axial directions due to the J-effect, it is clearly visible in the second position, which presents the second time snapshot. In the third snapshot, the viruses, most distant to the centreline, have already travelled to the vicinity of the fibre surface. They are captured by the surface in the next time snapshot. In the last snapshot the other viruses are filtered out to the caverns and only the virus on the centreline stays in the

A
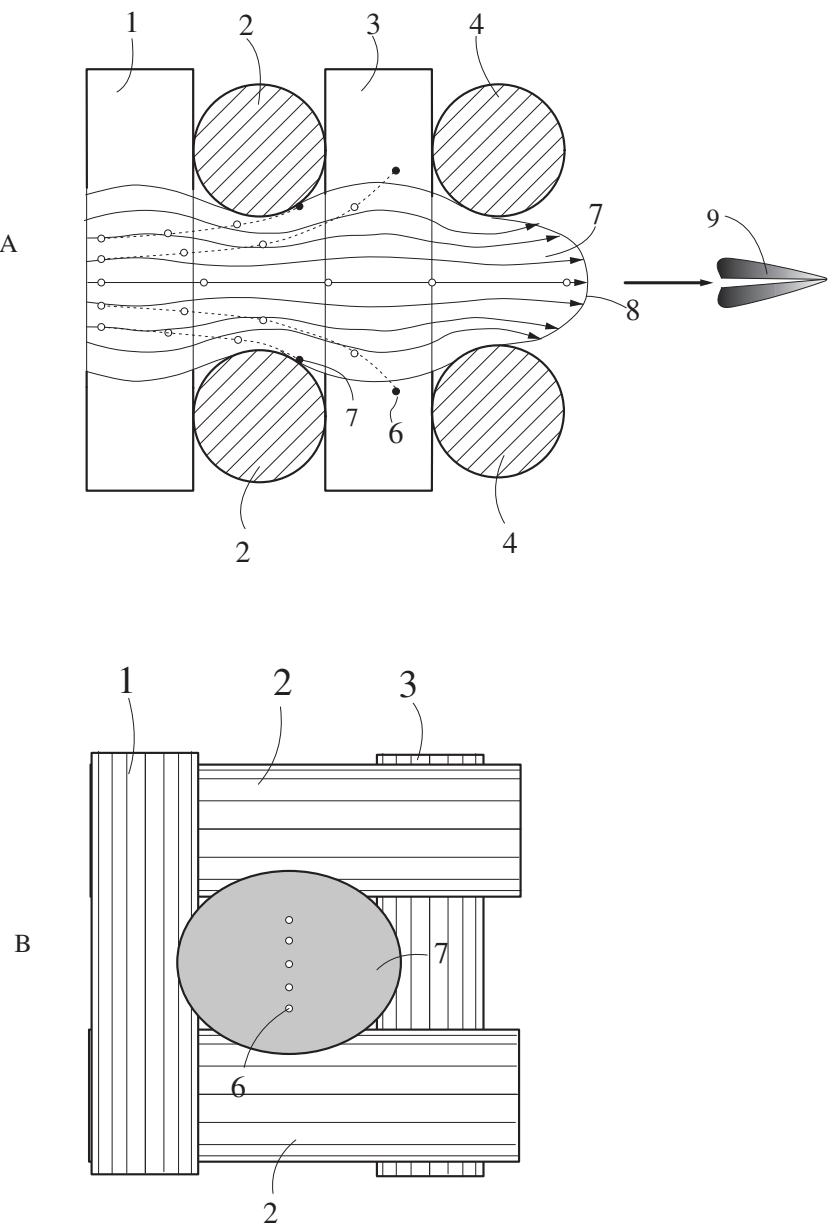

Fig. 19. Inhalation - illustration of a movement of small particles, which would exhibit Brownian motion in a still air. 
airflow. This means, that there is no particles larger than 10nm left in the airflow that might be filtered out in the diffusion process. It is clear that the diffusion process does not apply here.

The frozen state between the inhalation and exhalation (undisturbed period) is shown in figure 20. There are no streamlines and the channel and cavern form a single space and thus enabling the diffusion exchange of the particles between the channel and cavern and filtering based on the Brownian motion.

In the figure 21 the phenomenology is the same as in figure 19, just the direction of the airflow is reversed.
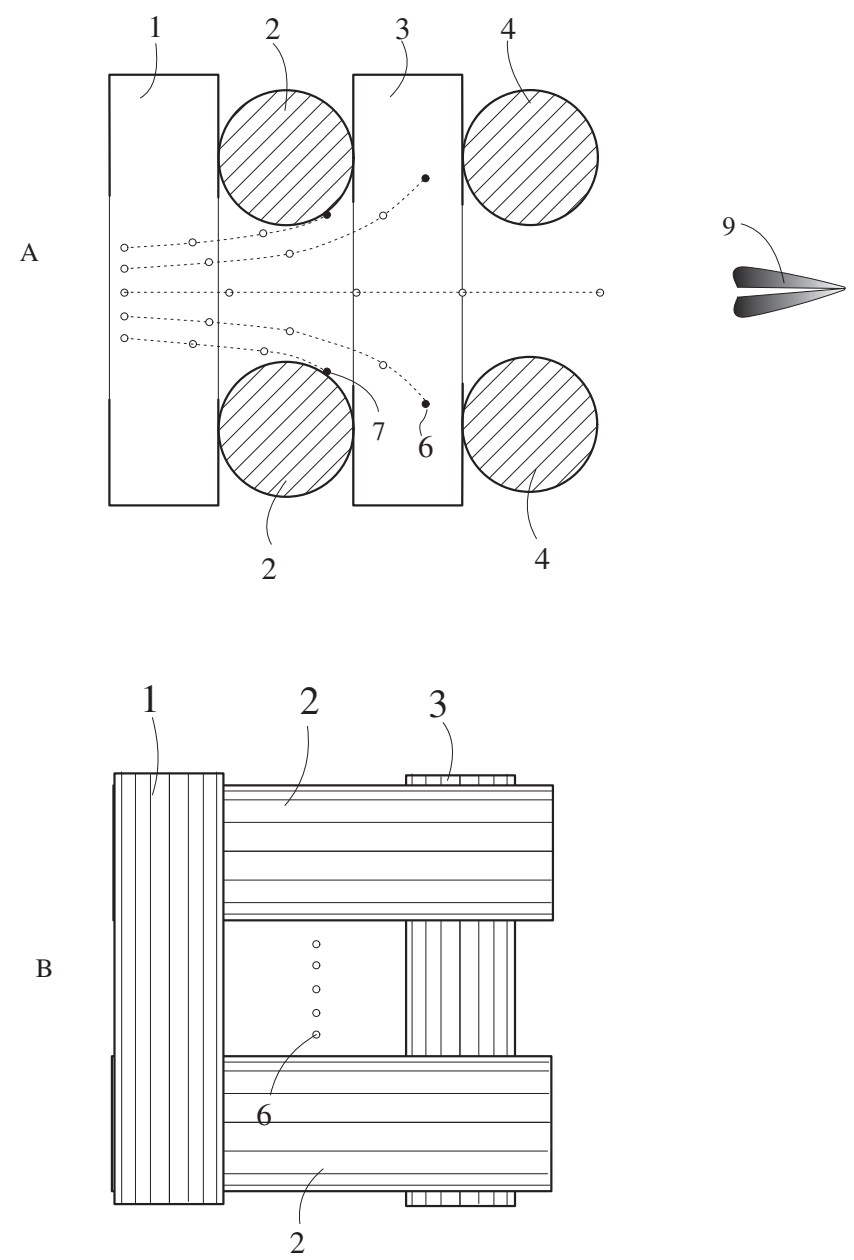

Fig. 20. Undisturbed period between the inhalation and exhalation. 
A

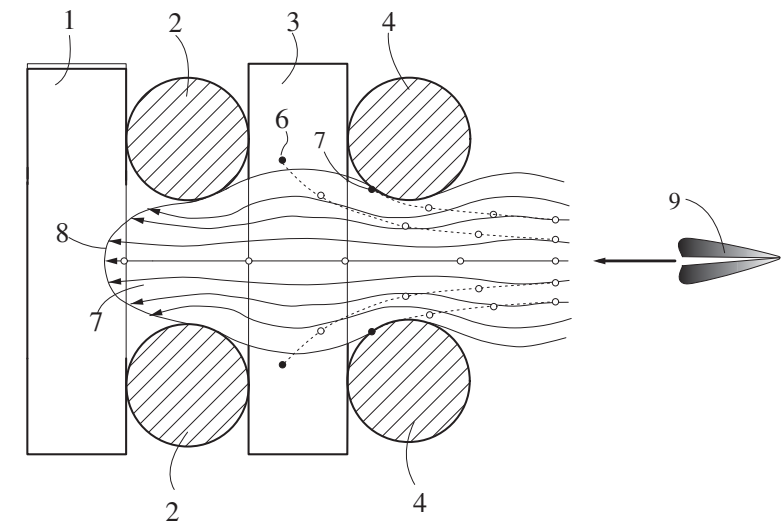

B

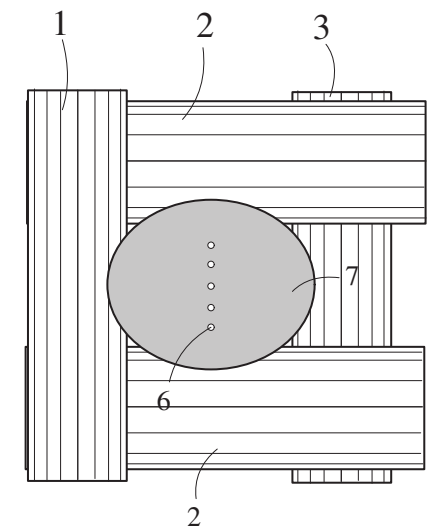

Fig. 21. Exhalation - illustration of a movement of small particles. 


\section{Conclusions}

The novel approach to the filtering mechanisms of nano-particles through medical masks is presented in this chapter together with the criticism of the classical filtration theory.

The novel view on the filtration problem was enabled by development and usage of the J-method, which is the method for determining the porosity parameters in the flat textiles. The pores' hydraulic diameter distribution is one of the method's results, which considers that the channels are formed from one surface of a flat textile to the other one. The channel cross-section size is defined by the pore hydraulic diameter distribution. We showed that the air flow through channels is laminar and that the problem size is in domain of the continuous mechanics. The laminar air flow through channel forms distinctive velocity profile, which is responsible for driving the spherical virus rotation. The Magnus effect appears due to the self-induced rotation of the virus. The axial force is thus generated that is driving a virus toward the channel boundaries. This is named as J-effect.

The novel view on the filtration problem was enabled by development and usage of the J-method, which is the method for determining the porosity parameters in the flat textiles. The pores' hydraulic diameter distribution is one of the method's results, which considers that the channels are formed from one surface of a flat textile to the other one. The channel cross-section size is defined by the pore hydraulic diameter distribution. We showed that the air flow through channels is laminar and that the problem size is in domain of the continuous mechanics. The laminar air flow through channel forms distinctive velocity profile, which is responsible for driving the spherical virus rotation. The Magnus effect appears due to the self-induced rotation of the virus. The axial force is thus generated that is driving a virus toward the channel boundaries. This is named as J-effect.

The numerical investigation, using the computational fluid dynamics approach and the classical Newtonian mechanics, showed that the J-effect is a phenomenon that appears fast and is therefore an efficient mechanism of filtering spherical or near-spherical viruses even in the straight channel.

On the other hand, the Brownian motion of the particles trapped in the air flow as advocated by the classical filtration theory could be dismissed as unrealistic.

There are some questions that have not been addressed here but are also important for understanding of the complete filtration phenomenon. Some of them could be partially addressed by the classical filtration theory. The questions that arise with this analysis could be summarised as:

1. What is happening at the channel bend?

2. What is happening in the caverns?

3. How is the particle separated into a cavern?

4. What share of the particles is separated into cavern?

5. How the particle interaction is affecting the filtering process?

\section{References}

Brown, R. (1993). Air Filtration: An Integrated Approach to the Theory and Applications of Fibrous Filters, Pergamon Press. 
Hutten, I. (2007). Handbook of nonwoven filter media, Elsevier.

Jakšić, D. \& Jakšić, N. (2007). Assessment of porosity of flat textile fabrics, Textile Research Journal 77(2): $105-110$.

Jakšić, D. \& Jakšić, N. (2010). Woven fabric engineering, Sciyo, cop., chapter Porosity of the flat textiles (Chapter 14), pp. 255 - 272.

URL: http://www.intechopen.com/books/show/title/woven-fabric-engineering

Sharma, A. (2000). Penetration, pressure drop, and wicking characteristics of niosh certified p-100 and p-95 filters under heavy dop holding, Master's thesis, College of Engineering and Mineral Resources at West Virginia University.

Widden, M. (1966). Fluid Mechanics, Macmillan Press.

Wikipedia (2011). http:/ /en.wikipedia.org/wiki/rotavirus.

URL: http://en.wikipedia.org/wiki/Rotavirus

Zuurbier, M., Hoek, H., Hazel, P. \& Brunekreef, B. (2009). Minute ventilation of cyclists, car and bus passengers: an experimental study, Environmental Health 8(48): 0 - 0 .

URL: http://www.ehjournal.net/content/8/1/48 


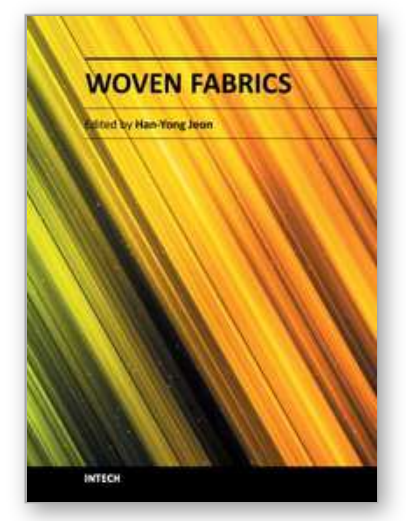

\author{
Woven Fabrics \\ Edited by Prof. Han-Yong Jeon
}

ISBN 978-953-51-0607-4

Hard cover, 296 pages

Publisher InTech

Published online 16, May, 2012

Published in print edition May, 2012

"Woven Fabrics" is a unique book which covers topics from traditional to advanced fabrics widely used in IT, NT, BT, ET, ST industry fields. In general, woven fabrics are known as the traditional textile fabrics for apparel manufacturing and are used widely in various fabric compositions as intermediate goods that affect human activities. The relative importance of woven fabrics as traditional textile materials is extremely large and currently application fields of woven fabrics as technical textiles are rapidly expanded by utilizing its geometric features and advantages. For example, the book covers analytical approaches to fabric design, micro and nano technology needed to make woven fabrics, as well as the concept for industrial application.

\title{
How to reference
}

In order to correctly reference this scholarly work, feel free to copy and paste the following:

Nikola Jakšić and Danilo Jakšić (2012). Novel Theoretical Approach to the Filtration of Nano Particles Through Non-Woven Fabrics, Woven Fabrics, Prof. Han-Yong Jeon (Ed.), ISBN: 978-953-51-0607-4, InTech, Available from: http://www.intechopen.com/books/woven-fabrics/novel-theoretical-approach-to-the-filtration-of-nanoparticles-through-non-woven-fabrics

\section{INTECH}

open science | open minds

\section{InTech Europe}

University Campus STeP Ri Slavka Krautzeka 83/A 51000 Rijeka, Croatia

Phone: +385 (51) 770447

Fax: +385 (51) 686166 www.intechopen.com

\section{InTech China}

Unit 405, Office Block, Hotel Equatorial Shanghai No.65, Yan An Road (West), Shanghai, 200040, China 中国上海市延安西路65号上海国际贵都大饭店办公楼 405 单元 Phone: +86-21-62489820

Fax: +86-21-62489821 
(C) 2012 The Author(s). Licensee IntechOpen. This is an open access article distributed under the terms of the Creative Commons Attribution 3.0 License, which permits unrestricted use, distribution, and reproduction in any medium, provided the original work is properly cited. 